\title{
Perilla frutescens Leaf Extract and Fractions: Polyphenol Composition, Antioxidant, Enzymes ( $\alpha$-Glucosidase, Acetylcholinesterase, and Tyrosinase) Inhibitory, Anticancer, and Antidiabetic Activities
}

\author{
Zhenxing Wang ${ }^{1,2} \mathbb{D}$, Zongcai Tu ${ }^{1,3,4,5, *}$, Xing Xie ${ }^{5}$, Hao Cui ${ }^{3}$, Kin Weng Kong ${ }^{6}$ and Lu Zhang ${ }^{1,3,4}$ \\ 1 College of Chemistry and Chemical Engineering, Jiangxi Normal University, Nanchang 330022, China; \\ wangzhenxingfood@163.com (Z.W.); zhanglu00104@163.com (L.Z.) \\ 2 College of Life Sciences, Southwest Forestry University, Kunming 650224, China \\ 3 College of Life Sciences, Jiangxi Normal University, Nanchang 330022, China; cuihaoeric@jxnu.edu.cn \\ 4 National R\&D Center for Freshwater Fish Processing, Jiangxi Normal University, Nanchang 330022, China \\ 5 State Key Laboratory of Food Science and Technology, Nanchang University, Nanchang 330047, China; \\ 13609092537@126.com \\ 6 Department of Molecular Medicine, Faculty of Medicine, University of Malaya, Kuala Lumpur 50603, \\ Malaysia; kongkm@um.edu.my \\ * Correspondence: 004756@jxnu.edu.cn; Tel.: +86-791-8812-1868
}

check for updates

Citation: Wang, Z.; Tu, Z.; Xie, X.; Cui, H.; Kong, K.W.; Zhang, L. Perilla frutescens Leaf Extract and Fractions:

Polyphenol Composition, Antioxidant, Enzymes ( $\alpha$-Glucosidase,

Acetylcholinesterase, and Tyrosinase) Inhibitory, Anticancer, and

Antidiabetic Activities. Foods 2021, 10, 315. https://doi.org/10.3390/foods 10020315

Academic Editor: Kwang-Geun Lee Received: 16 January 2021

Accepted: 30 January 2021

Published: 3 February 2021

Publisher's Note: MDPI stays neutral with regard to jurisdictional claims in published maps and institutional affiliations.

Copyright: (c) 2021 by the authors Licensee MDPI, Basel, Switzerland. This article is an open access article distributed under the terms and conditions of the Creative Commons Attribution (CC BY) license (https:// creativecommons.org/licenses/by/ $4.0 /)$.

\begin{abstract}
This study aims to evaluate the bioactive components, in vitro bioactivities, and in vivo hypoglycemic effect of $P$. frutescens leaf, which is a traditional medicine-food homology plant. $P$. frutescens methanol crude extract and its fractions (petroleum ether, chloroform, ethyl acetate, nbutanol fractions, and aqueous phase residue) were prepared by ultrasound-enzyme assisted extraction and liquid-liquid extraction. Among the samples, the ethyl acetate fraction possessed the high total phenolic ( $440.48 \mu \mathrm{g}$ GAE/mg DE) and flavonoid content (455.22 $\mu \mathrm{g}$ RE/mg DE), the best antioxidant activity (the DPPH radical, ABTS radical, and superoxide anion scavenging activity, and ferric reducing antioxidant power were 1.71, 1.14, 2.40,1.29, and 2.4 times higher than that of control Vc, respectively), the most powerful $\alpha$-glucosidase inhibitory ability with the $\mathrm{IC}_{50}$ value of $190.03 \mu \mathrm{g} / \mathrm{mL}$ which was 2.2-folds higher than control acarbose, the strongest proliferative inhibitory ability against MCF-7 and HepG2 cell with the $\mathrm{IC}_{50}$ values of 37.92 and $13.43 \mu \mathrm{g} / \mathrm{mL}$, which were considerable with control cisplatin, as well as certain inhibition abilities on acetylcholinesterase and tyrosinase. HPLC analysis showed that the luteolin, rosmarinic acid, rutin, and catechin were the dominant components of the ethyl acetate fraction. Animal experiments further demonstrated that the ethyl acetate fraction could significantly decrease the serum glucose level, food, and water intake of streptozotocin-induced diabetic SD rats, increase the body weight, modulate their serum levels of TC, TG, HDL-C, and LDL-C, improve the histopathology and glycogen accumulation in liver and intestinal tissue. Taken together, $P$. frutescens leaf exhibits excellent hypoglycemic activity in vitro and in vivo, and could be exploited as a source of natural antidiabetic agent.
\end{abstract}

Keywords: P. frutescens leaf; phytochemical composition; antioxidant activity; enzyme inhibitory; anticancer ability; antidiabetic activity

\section{Introduction}

Type 2 diabetes mellitus (T2DM), which is characterized by postprandial hyperglycemia and chronic hyperglycemia, is one of the most serious metabolic diseases worldwide and its pathogenesis is associated with oxidative stress [1]. Oxidative stress is an imbalance between reactive oxygen species (ROS) and cellular antioxidative systems; excessive ROS accumulation induces oxidative stress, leading to cell damage, which in turn is involved in diabetes and various complications [2]. Furthermore, many other metabolic diseases are also associated with oxidative stress, including obesity, cancer, neurodegenerative 
disorders, and cardiovascular complications [3]. Indeed, these diseases also influence each other through the metabolic abnormalities associated with oxidative stress, for example, there is a close and direct link between diabetes and Alzheimer's disease (AD) [4]. In addition, cancer development may lead to the aggravation of an underlying diabetic condition [5]. Consumption of antioxidant-rich foods has been considered to have the ability to potentially modulate oxidative stress, which in turn, has beneficial impacts on oxidative stress-related diseases [6]. Natural antioxidant products, especially polyphenol (flavonoid)rich sources, such as edible medicinal herbs, fruits, vegetables, cereals, teas, and seeds, have attracted more attention because of their advantages in safety, effectiveness, and non-toxic properties. Ever-growing consumer demand for healthy, combined with a preference for natural ingredients, has led to very big growth in plant-based extracts functional foods and dietary supplements markets in recent years, especially during coronavirus disease 2019 (COVID-19) outbreak [7-10].

P. frutescens (L.) Britt. is a common annual Labiatae planted in the Southeast Asian region, and the most frequently used part is the leaf. In addition to the use as a green leafy vegetable, spice, and flavoring agent in food processing, P. frutescens leaves are widely used in traditional Chinese medicine to treat common cold, diarrhea, fever, cough, vomiting, and more. Modern pharmacological studies have demonstrated that P. frutescens leaves contain rich bioactive components, like phenolics, flavonoids, anthocyanins, tannins, and essential oil, and exhibited a variety of activities, including antioxidant, antiallergy, antiinflammation, antitumor, and antibacterial activities [11-14]. In our previous study, the methanol crude extract of $P$. frutescens leaves exhibited a promising $\alpha$-glucosidase inhibitory ability after an in vitro gastrointestinal digestion, which exhibited the therapeutic potential in diabetes [15], this was also evidenced by other previous research [16,17]. However, the majority of studies on the hypoglycemic effect of $P$. frutescens leaves have been conducted in vitro, with very little report conducted at the animal level.

In this study, the antioxidant activities, $\alpha$-glucosidase, acetylcholinesterase, tyrosinase inhibition abilities, and anticancer abilities of $P$. frutescens leaves extracts prepared with solvents at different polarities were determined in order to assess their abilities in preventing and treating oxidative stress-related diseases. Then, the fraction with high content of phenolics and flavonoids and good bioactivity were quantified by high-performance liquid chromatography (HPLC), and its antidiabetic effects were further evaluated using diabetic rats. The findings of present work could provide a new reference for the development of novel antidiabetic drugs.

\section{Materials and Methods}

\subsection{Chemicals and Reagents}

All chemical reagents including methanol, petroleum ether (PE), chloroform (CF), ethyl acetate (EtOAc), and n-butanol $(\mathrm{n}-\mathrm{BuOH})$ were purchased from Sinopharm Chemical Reagent Co., Ltd. (Shanghai, China). Folin-Ciocalteu, pyrogallol, and other analytical grade chemicals were purchased from Aladdin (Shanghai, China). Chromatographic acetonitrile was purchased from Merck (Darmstadt, Germany). Gallic acid and other standards for HPLC were purchased from Yuanye Bio-Technology (Shanghai, China). Cellulase $(3000 \mathrm{U} / \mathrm{g})$ and pectinase $(40,000 \mathrm{U} / \mathrm{g})$ were purchased from Xiya reagent (Shandong, China). $\alpha$-glucosidase from Saccharomyces cerevisiae (G5003), acarbose, 4methylumbelliferyl $\alpha$-D-glucopyranoside (4-MUG), acetylcholinesterase (AChE) from Electrophorus electricus (C3389), galanthamine (GAL), acetylthiocholine iodide (ATCI), 5,5-dithiobis-(2-nitrobenzoic acid) (DTNB), tyrosinase from mushroom (T3824), kojic acid, 3,4-Dihydroxy-L-phenylalanine (L-dopa), cisplatin, and streptozocin (STZ) were purchased from Sigma-Aldrich (St. Louis, MO, USA).

The MCF-7 and HepG2 cells were purchased from Conservation genetics CAS Kunming cell bank. Dulbecco's modified Eagle's medium (DMEM), fetal bovine serum (FBS), and other cell culture reagents were purchased from Gibco (Carlsbad, CA, USA). Cell counting kit-8 (CCK-8) reagent was purchased from Dojindo (Kumamoto, Japan). 


\subsection{Samples Preparation}

The leaves of $P$. frutescens (L.) Britt were purchased from a farm $\left(24^{\circ} 32^{\prime} 44^{\prime \prime} \mathrm{N}, 116^{\circ} 15^{\prime} 12^{\prime \prime} \mathrm{E}\right)$ in Meizhou city, Guangdong, China. Extraction was done by referring to the previous method [18]. Briefly, $1.5 \mathrm{~kg}$ of sun-dried powdered leaves (moisture content ranges of $10-14 \%$ ) was mixed in a 6-fold volume (volume to mass ratio) of pure water, the solution was adjusted to $\mathrm{pH}$ of 5 with hydrochloric acid $(\mathrm{HCl} 1 \mathrm{M})$, then $0.67 \%$ cellulase and $0.05 \%$ pectinase were added, followed by ultrasound-assisted enzymatic hydrolysis was performed at $400 \mathrm{~W}, 50{ }^{\circ} \mathrm{C}$ for $60 \mathrm{~min}$. After hydrolysis, methanol was added until $70 \%$ final concentration and the solution volume was adjusted to 20 -fold volume (70\% methanol volume to samples mass ratio). Subsequently, ultrasound-assisted extraction of this mixture was performed two times in the same condition as before. The extract was evaporated under reduced pressure at $50{ }^{\circ} \mathrm{C}$ to yield $198 \mathrm{~g}$ of dry crude extract (CE), which was then suspended in $5 \mathrm{~L} \mathrm{H}_{2} \mathrm{O}$ and extracted twice with an equal volume of organic solvent of different polarities successively, and the solvents used for the extractions were $\mathrm{PE}$ (polarity 0.1), CF (polarity 4.1), EtOAc (polarity 4.4), and n- $\mathrm{BuOH}$ (polarity 3.7). The resulting solvent fractions were collected and all solvents were removed under reduced pressure and lyophilized to yield $27.26 \mathrm{~g}$ PE, $15.48 \mathrm{~g} \mathrm{CF}, 49.49 \mathrm{~g}$ EtOAc, and $50.11 \mathrm{~g} \mathrm{n}-\mathrm{BuOH}$ fractions, and $52.13 \mathrm{~g}$ aqueous phase residue (AQ). All the samples were kept at $-20{ }^{\circ} \mathrm{C}$ for further analysis.

\subsection{Determination of Bioactive Compounds}

\subsubsection{Total Phenolic Content}

The total phenolic content (TPC) was assessed using the Folin-Ciocalteu colorimetric assay [19]. A $40 \mu \mathrm{L}$ of the properly diluted sample was added to a 96-well microplate and mixed with $20 \mu \mathrm{L}$ of $0.5 \mathrm{M}$ Folin-Ciocalteu reagents, kept for $5 \mathrm{~min}$ at $25^{\circ} \mathrm{C}$. A $160 \mu \mathrm{L}$ of $\mathrm{Na}_{2} \mathrm{CO}_{3}(7.5 \%, w / v)$ was then added and incubated, protected from light, for $30 \mathrm{~min}$ at $25{ }^{\circ} \mathrm{C}$. Finally, the absorbance value was measured at $765 \mathrm{~nm}$ by a microplate reader (Biotek, VT, USA). Gallic acid (10-100 $\mu \mathrm{g} / \mathrm{mL})$ was used as the standard and results were expressed as $\mu \mathrm{g}$ of gallic acid equivalents (GAE)/mg dry extract (DE).

\subsubsection{Total Flavonoid Content}

The total flavonoid content (TFC) was measured using a previously reported method [20]. An exact volume of $40 \mu \mathrm{L}$ of appropriately diluted sample was mixed with $3 \% \mathrm{NaNO}_{2}$ $(20 \mu \mathrm{L})$ and kept for $6 \mathrm{~min}, 20 \mu \mathrm{L}$ of a $6 \% \mathrm{Al}\left(\mathrm{NO}_{3}\right)_{3}$ was then added and allowed to react for $6 \mathrm{~min}$, followed by addition of $140 \mu \mathrm{L}$ of $4 \% \mathrm{NaOH}$, and also $60 \mu \mathrm{L}$ of $70 \%$ methanol. The mixture was incubated at room temperature for $15 \mathrm{~min}$ and absorbance was determined at a wavelength of $510 \mathrm{~nm}$. Rutin $(10-100 \mu \mathrm{g} / \mathrm{mL})$ was used as the standard reference, and the final result was expressed as $\mu \mathrm{g}$ of rutin equivalents (RE)/mg dry extract (DE).

\subsection{Determination of Antioxidant Activity}

\subsubsection{DPPH Radical Scavenging Activity}

The DPPH. scavenging activity was quantified by the method reported by Chan et al. [21], with Trolox as the standard. The suitable concentration of sample $(100 \mu \mathrm{L})$ was mixed with $100 \mu \mathrm{L} 0.15 \mathrm{mM}$ DPPH solution in a 96-well microplate, then the mixtures were kept in darkness for $30 \mathrm{~min}$ at room temperature. Subsequently, the absorbance was measured at $517 \mathrm{~nm}$. By plotting the elimination ratio versus the corresponding concentrations of Trolox $(20-100 \mu \mathrm{g} / \mathrm{mL})$, a standard reference was prepared and the $\mathrm{DPPH}$. scavenging activity was calculated. The results were expressed as $\mu \mathrm{g}$ of Trolox equivalents/mg dry extract (DE). Methanol was used as a negative control, whereas ascorbic acid (Vc) and BHT were used as positive controls.

\subsubsection{ABTS Radical Scavenging Activity}

The ABTS. ${ }^{+}$scavenging activity was estimated following the reported method [22], with a slight modification. Briefly, ABTS ${ }^{+}$solution was prepared by mixing $7 \mathrm{mM}$ ABTS 
aqueous solution with $2.45 \mathrm{mM}$ potassium persulphate, and incubated in the dark at $25{ }^{\circ} \mathrm{C}$ for $12 \mathrm{~h}$ to afford an absorbance value of $0.7 \pm 0.2$ at $734 \mathrm{~nm}$. A $50 \mu \mathrm{L}$ of the properly diluted sample was added to $200 \mu \mathrm{L} \mathrm{ABTS}^{+}$solution in a 96-well microplate and incubated at room temperature for $6 \mathrm{~min}$, then the absorbance was measured at $734 \mathrm{~nm}$. Trolox was used as a standard, methanol was used as a negative control, whereas Vc and BHT were used as positive controls. The ABTS. ${ }^{+}$scavenging activity was expressed as $\mu \mathrm{g}$ of Trolox equivalents/mg dry extract (DE).

\subsubsection{Ferric Reducing Antioxidant Power}

The ferric reducing antioxidant power (FRAP) was determined according to our previously reported method [23]. FRAP reagent consisted of $7 \mathrm{mM} \mathrm{TPTZ,} 20 \mathrm{mM} \mathrm{FeCl}_{3}$ in acetate buffer ( $\mathrm{pH}$ 3.6). A $50 \mu \mathrm{L}$ of the suitable concentration of sample was mixed with $200 \mu \mathrm{L}$ of FRAP reagent in a 96-well microplate and protected from light at $37^{\circ} \mathrm{C}$. After incubation for $10 \mathrm{~min}$, the absorbance at $593 \mathrm{~nm}$ was measured. $\mathrm{FeSO}_{4}(20-100 \mu \mathrm{g} / \mathrm{mL})$ was used as a standard, methanol was used as a negative control, whereas Vc and BHT were used as positive controls. The FRAP value was expressed as $\mu \mathrm{g}$ of $\mathrm{FeSO}_{4}$ equivalents/mg dry extract (DE).

\subsubsection{Superoxide Radical Scavenging Activity}

The superoxide anion $\left(\mathrm{O}_{2}{ }^{-}\right)$scavenging activity was examined using a pyrogallol autoxidation method [24]. Briefly, a $20 \mu \mathrm{L}$ of appropriately diluted sample solution was added to $240 \mu \mathrm{L}$ Tris- $\mathrm{HCl}$ buffer (50 mM, pH 8.2, containing $1 \mathrm{mM} \mathrm{Na} 2$ EDTA) in a 96well microplate. After incubation in darkness at room temperature for $10 \mathrm{~min}, 20 \mu \mathrm{L}$ of pyrogallol $(60 \mathrm{mM}$, prepared in $1 \mathrm{mM} \mathrm{HCl})$ was added. Followed by oscillation for $10 \mathrm{~s}$, the absorbance at $325 \mathrm{~nm}$ was measured immediately every minute for $5 \mathrm{~min}$, and the slope of the absorbance vs. time plot was calculated. The superoxide radical scavenging activity of samples were defined as the degree of autoxidation rate reduction. Trolox was used to generate a standard reference curve and results were expressed as $\mathrm{mg}$ Trolox equivalents/g dry extract (DE). Methanol was used as the negative control, whereas $\mathrm{V}_{\mathrm{c}}$ and $\mathrm{BHT}$ were used as the positive controls.

\subsection{Determination of Enzymes Inhibitory Activity \\ 2.5.1. $\alpha$-Glucosidase Inhibitory Ability}

The $\alpha$-glucosidase inhibitory ability was assessed as our previous study [15]. A $50 \mu \mathrm{L}$ of the suitable concentration of sample was mixed with $20 \mu \mathrm{L}$ of $0.1 \mathrm{U} / \mathrm{mL} \alpha-$ glucosidase in a black 96-well microplate, then $50 \mu \mathrm{L}$ of $84 \mu \mathrm{M}$ freshly prepared 4-MUG solution was added and incubated in darkness for $20 \mathrm{~min}$ at $37^{\circ} \mathrm{C}$. Finally, the reaction was stopped by the addition of $100 \mu \mathrm{L}$ of $100 \mathrm{mM}$ glycine- $\mathrm{NaOH}$ buffer ( $\mathrm{pH}$ 10.6). Followed by shaking on an orbital shaker for $30 \mathrm{~s}$, the fluorescence value at $\lambda_{\text {ex }} 355 \mathrm{~nm}$ and $\lambda_{\mathrm{em}}$ $460 \mathrm{~nm}$ was measured. Methanol and acarbose were negative and positive controls, respectively. Results were expressed as $\mathrm{IC}_{50}$ value $(\mu \mathrm{g} / \mathrm{mL})$, which was calculated by nonlinear regression analysis between the percentage of inhibition and sample concentration.

\subsubsection{Acetylcholinesterase Inhibitory Ability}

The acetylcholinesterase (AChE) inhibitory properties of the extracts were tested using a 96-well microplate colorimetric method [25]. A $50 \mu \mathrm{L}$ of the suitable concentration of sample was mixed with $90 \mu \mathrm{L}$ of Ellman's solution (containing $15 \mu \mathrm{L}$ of $15 \mathrm{mM}$ ATCI and $75 \mu \mathrm{L}$ of $3 \mathrm{mM}$ DTNB) in a 96-well microplate and incubated in darkness for $10 \mathrm{~min}$ at $30{ }^{\circ} \mathrm{C}$. Then $20 \mu \mathrm{L}$ of $0.2 \mathrm{U} / \mathrm{mL}$ AChE was added and kept in darkness for $5 \mathrm{~min}$. Finally, the absorbance value at $405 \mathrm{~nm}$ was measured. Methanol and galanthamine were negative and positive controls, respectively. The AChE inhibitory ability was expressed as $\mathrm{IC}_{50}$ value $(\mathrm{mg} / \mathrm{mL})$. 


\subsubsection{Tyrosinase Inhibitory Ability}

The tyrosinase inhibitory ability was determined according to the reported method [26], with little modification. First, $50 \mu \mathrm{L}$ of the suitable concentration of the sample was added to $150 \mu \mathrm{L}$ of mushroom tyrosinase solution $(100 \mathrm{U} / \mathrm{mL})$ and incubated for $15 \mathrm{~min}$ at $37^{\circ} \mathrm{C}$, followed by $50 \mu \mathrm{L}$ of $2.5 \mathrm{mM}$ L-dopa was added and reacted at $37^{\circ} \mathrm{C}$ for $10 \mathrm{~min}$, the absorbance value was measured at $475 \mathrm{~nm}$. Methanol was used as the solvent control, while kojic acid was used as the positive control, and results were expressed as $\mathrm{IC}_{50}$ value $(\mu \mathrm{g} / \mathrm{mL})$.

\subsection{Determination of Anticancer Activity}

The inhibition on HepG2 and MCF-7 cell proliferation was measured by using the CCK-8 assay according to our previous report [15]. Cells were seeded in 96-well plates $\left(5 \times 10^{3}\right.$ cells per well) and placed in a cell culture incubator at $37^{\circ} \mathrm{C}$. After $24 \mathrm{~h}$ of incubation, a $10 \mu \mathrm{L}$ of the suitable concentration of sample was added and kept for $24 \mathrm{~h}$, followed by the addition of CCK-8 solution $(10 \mu \mathrm{L})$, cells were incubated for a further $4 \mathrm{~h}$, the absorbance at $450 \mathrm{~nm}$ was measured. Cisplatin was used as a positive control. The cell proliferation inhibitory ability was expressed as the $\mathrm{IC}_{50}$ value $(\mu \mathrm{g} / \mathrm{mL})$. In addition, the cytotoxic effect was also evaluated by measuring the viability of cells after treatment with the sample for $48 \mathrm{~h}$.

\subsection{HPLC-DAD Analyses}

HPLC-DAD analysis was performed by an HPLC 1260 (Agilent Technologies, CA, USA) equipped with a degasser, quaternary pump solvent delivery, thermo-stated column compartment, and a diode array detector (DAD). Chromatographic separations were performed on the C18 reversed-phase analytical column $(250 \mathrm{~mm} \times 4.6 \mathrm{~mm}, 5 \mu \mathrm{m}$, Greenherbs Science and Technology) at $25{ }^{\circ} \mathrm{C}$, while $0.1 \%$ formic acid (A) and acetonitrile (B) were used as the mobile phases with a flow rate of $0.8 \mathrm{~mL} / \mathrm{min}$. The gradient elution conditions of the mobile phase B were: $0-12 \mathrm{~min}, 2-8 \%$; $12-15 \mathrm{~min}, 8-13 \%$; $15-30 \mathrm{~min}, 13-18 \%$; $30-50 \mathrm{~min}$, 18-30\%; 50-60 min, 30-50\%; 60-70 $\mathrm{min}, 50-70 \%$; 70-80 $\mathrm{min}, 70-90 \%$; 80-85 $\mathrm{min}, 90-100 \%$; $85-90 \mathrm{~min}, 100-2 \%$. Samples were filtered through nylon syringe filters $(0.22 \mu \mathrm{m})$ and injected in triplicate with an injection volume of $20 \mu \mathrm{L}$. The chromatogram was monitored from 200 to $400 \mathrm{~nm}$ and the peak areas were calculated. Finally, compounds were identified and quantified by comparison with the retention times and peak areas from standards. In this study, five-point calibration curves were prepared using gallic acid $(y=662.72 x+73.856$, $\left.R^{2}=0.9995\right)$ at $280 \mathrm{~nm}$, catechin $\left(\mathrm{y}=185.86 \mathrm{x}-26.949, R^{2}=0.9991\right)$ at $280 \mathrm{~nm}$, chlorogenic acid ( $\left.\mathrm{y}=336.05 \mathrm{x}-1.1845, R^{2}=0.9998\right)$ at $310 \mathrm{~nm}$, L-epicatechin $(\mathrm{y}=213.05 \mathrm{x}+16.625$, $\left.R^{2}=0.9983\right)$ at $280 \mathrm{~nm}$, dihydromyricetin $\left(\mathrm{y}=446.13 \mathrm{x}+23.478, R^{2}=0.9994\right)$ at $280 \mathrm{~nm}$, rutin $\left(\mathrm{y}=128.39 \mathrm{x}+0.3309, R^{2}=0.9972\right)$ at $360 \mathrm{~nm}$, ferulic acid $\left(\mathrm{y}=484.56 \mathrm{x}+1.9186, R^{2}=0.9997\right)$ at $340 \mathrm{~nm},(-)$-epicatechin gallate $\left(\mathrm{y}=413.08 \mathrm{x}+89.615, R^{2}=0.9954\right)$ at $280 \mathrm{~nm}$, rosmarinic $\operatorname{acid}\left(\mathrm{y}=274.64 \mathrm{x}-27.312, R^{2}=0.9993\right)$ at $310 \mathrm{~nm}$, baicalin $\left(\mathrm{y}=324.12 \mathrm{x}-1.6326, R^{2}=0.9974\right)$ at $310 \mathrm{~nm}$, luteolin $\left(\mathrm{y}=20.373 \mathrm{x}-1.2548, R^{2}=0.9963\right)$ at $360 \mathrm{~nm}$, apigenin $(\mathrm{y}=472.77 \mathrm{x}-0.899$, $\left.R^{2}=0.9993\right)$ at $340 \mathrm{~nm}$, hesperetin $\left(\mathrm{y}=247.1 \mathrm{x}+15.53, R^{2}=0.9992\right)$ at $310 \mathrm{~nm}$, baicalein $\left(\mathrm{y}=239.15 \mathrm{x}-31.549, R^{2}=0.9985\right)$ at $340 \mathrm{~nm}$, myricetin $\left(\mathrm{y}=226.05 \mathrm{x}-7.4156, R^{2}=0.9965\right)$ at $360 \mathrm{~nm}$, quercetin $\left(\mathrm{y}=264.13 \mathrm{x}+8.0285, R^{2}=0.9995\right)$ at $360 \mathrm{~nm}$, and resveratrol $(\mathrm{y}=289.2 \mathrm{x}$ $\left.-5.31, R^{2}=0.9998\right)$ at $340 \mathrm{~nm}$, where $\mathrm{x}$ was concentration, and $\mathrm{y}$ was area peak, and the concentration of all samples ranged varied from 20 to $100 \mu \mathrm{g} / \mathrm{mL}$. The results were expressed as $\mu \mathrm{g}$ equivalents of the corresponding standard per mg of extract.

\subsection{Determination of Antidiabetic Activity}

\subsubsection{Animals and Treatments}

The animal rats were purchased from Hunan SJA Laboratory Animal Co., Ltd. (Changsha, Hunan) and the production certificate number and use license number are SCXK (Hunan) 2016-0002 and SYXK (Hunan) 2016-0002, respectively. All animal experiments were done in the animal laboratories of Southwest Forestry University (Kunming, Yun- 
nan), and adhered to the guidelines for care and use of laboratory animals, and approved by the Academic Committee of Southwest Forestry University (ethical approval number SWFU-2018003). In this study, the T2DM rat model was induced by the method described previously [27] with some modifications. Briefly, thirty specific-pathogen-free SpragueDawley (SD) male rats (8-week-old, $200 \pm 20 \mathrm{~g}$ ) were housed in a room with a constant temperature $\left(23 \pm 2{ }^{\circ} \mathrm{C}\right)$ and humidity $(55 \pm 5 \%)$, one per cage, under a $12 \mathrm{~h} \mathrm{light/dark}$ cycle with free access to food and water. After a week of adaptation, the model groups were fed a high-fat diet (TP23400, $60 \%$ fat, $14.1 \%$ protein, and $25.9 \%$ carbohydrate, TROPHIC Animal Feed High-Tech Co. LTD, China) for 4 weeks, while the normal group was fed a normal diet (TP23402, 10\% fat, $14.1 \%$ protein, and $75.9 \%$ carbohydrate). Thereafter, the model groups were given an intraperitoneal injection of a low single dose of a freshly prepared STZ solution ( $45 \mathrm{mg} / \mathrm{kg}$ in $0.1 \mathrm{M}$ citrate buffer; $\mathrm{pH} 4.0$ ) after fasting for $12 \mathrm{~h}$, the normal group received an equal volume of citrate buffer. Three days after injection, the level of blood glucose was measured via the tail vein with a blood glucose meter (OneTouch Ultra, Johnson \& Johnson, USA) and rats with glucose concentration $>16.7 \mathrm{mmol} / \mathrm{L}$ were considered as type 2 diabetic rats. After successful modeling, the rats were randomly divided into five groups (6 rats per group): normal diet (ND), high-fat diet (HFD), high-fat diet with medium dose extracts (HFD-ME), high-fat diet with high dose extracts (HFD-HE), and high-fat diet with acarbose (HFD-A). The P. frutescens leaf extract fraction with the strongest $\alpha$-glucosidase inhibitory activity and acarbose were added to feed and mixed thoroughly, and used as the treatment and reference drug respectively. The HFD-ME and HFD-HE groups were fed with the mixed diet with the extract fractions dose of 100 and $250 \mathrm{mg} / \mathrm{kg}$ body weight (BW) per day respectively, whereas the HFD-A group were received acarbose (100 mg/kg BW per day). The HFD and ND group were continued to feed with a high-fat diet and a normal diet, respectively. The administration period was 4 weeks, and BW, food and water intake, and postprandial blood glucose were recorded weekly.

\subsubsection{Blood and Tissue Sample Collection}

At the end of the experiment, after $12 \mathrm{~h}$ of fasting, the rats were sacrificed after being sedated with anesthesia, blood was collected from the heart and centrifuged at $4000 \times g$ for $10 \mathrm{~min}$ at $4{ }^{\circ} \mathrm{C}$, and the supernatant was collected and stored at $-80^{\circ} \mathrm{C}$ for subsequent analyses. The total cholesterol (TC), triglyceride (TG), low-density lipoprotein cholesterol (LDL-C), and high-density lipoprotein cholesterol (HDL-C) levels were determined using an automatic biochemical analyzer (Abbott Laboratories, Abbott Park, Green Oaks, IL, USA). The liver and intestinal tissue were fixed in $4 \%$ paraformaldehyde solution, and embedded in paraffin and cut into 5- $\mu \mathrm{m}$ sections for hematoxylin and eosin (H\&E) staining and periodic acid-Schiff (PAS) staining, and assessed by light microscopy.

\subsection{Statistical Analysis}

All experiments were repeated three times to obtain the mean values (mean \pm standard deviation). Statistical analyses were carried out using SPSS 20.0 software (IBM, Armonk, NY, USA). Tukey's test and one-way analysis of variance were used to find significant differences, and a two-tailed Pearson test was used to analyze the correlation between different factors. $p<0.05$ was considered as significant $\left(^{*}\right)$, and $<0.01$ as highly significant ${ }^{(* *)}$. Principal component analysis (PCA) was performed using R (ver 3.6.3).

\section{Results}

\subsection{Total Phenolic and Flavonoid Content}

According to the previous report, P. frutescens leaves were found to be rich in phenolic and flavonoid components [28], which were the important secondary metabolites of many plants and exhibited a variety of biochemical and biological activities. The TPC and TFC of P. frutescens leave crude extract and the different fractions used in this study are displayed in Table 1. The results showed that TPC was highest in the crude extract (CE), followed by the ethyl acetate fraction (EtOAc), n-butanol fraction $(\mathrm{n}-\mathrm{BuOH})$, chloroform fraction $(\mathrm{CF})$, 
petroleum ether fraction (PE), and finally, the aqueous phase residue (AQ). The highest TFC was detected in the EtOAc, followed by the $\mathrm{CE}, \mathrm{CF}, \mathrm{n}-\mathrm{BuOH}, \mathrm{AQ}$, and PE. The phenolic and flavonoid concentrations differed greatly in various fractions (from $86.45 \pm 18.82$ to $440.48 \pm 13.08 \mu \mathrm{g}$ of GAE/mg DE, and from $85.68 \pm 18.82$ to $455.22 \pm 61.03 \mu \mathrm{g}$ of RE/mg $\mathrm{DE}$, respectively), which depended on the solvent polarity.

Table 1. Total phenolic and flavonoid content in P. frutescens leaf extract and its fractions.

\begin{tabular}{ccc}
\hline Samples & TPC $(\mu$ g of GAE/mg DE) & TFC $(\boldsymbol{\mu g}$ of RE/mg DE) \\
\hline CE & $450.83 \pm 11.74^{\mathrm{a}}$ & $411.69 \pm 43.50^{\mathrm{a}}$ \\
PE & $200.34 \pm 6.51^{\mathrm{c}}$ & $85.68 \pm 18.82^{\mathrm{c}}$ \\
CF & $281.31 \pm 8.57^{\mathrm{b}}$ & $384.24 \pm 3.53^{\mathrm{a}, \mathrm{b}}$ \\
EtOAc & $440.48 \pm 13.08^{\mathrm{a}}$ & $455.22 \pm 61.03^{\mathrm{a}}$ \\
n-BuOH & $419.78 \pm 48.88^{\mathrm{a}}$ & $307.86 \pm 12.10^{\mathrm{b}}$ \\
AQ & $86.45 \pm 18.82^{\mathrm{d}}$ & $104.00 \pm 31.69^{\mathrm{c}}$ \\
\hline
\end{tabular}

TPC $=$ total phenolic content; TFC $=$ total flavonoid content; $\mathrm{CE}=$ crude extract; PE = petroleum ether fraction $\mathrm{CF}=$ chloroform fraction; EtOAc $=$ ethyl acetate fraction; $\mathrm{n}-\mathrm{BuOH}=\mathrm{n}$-butanol fraction; $\mathrm{AQ}=$ aqueous phase residue. The different letters represent a significant difference, $p<0.05$.

\subsection{Antioxidant Properties}

In vitro antioxidant effect of $P$. frutescens leaf extract and its fractions were examined using four different assays (DPPH, $\mathrm{ABTS}^{+}, \mathrm{FRAP}$, and superoxide anion) and the results are depicted in Table 2. Among all the four antioxidant assays, EtOAc fraction displayed the best antioxidant activity and was significantly greater than the crude extract and other fractions $(p<0.05)$, with the values of $1006.33 \pm 15.80,1682.80 \pm 38.49$, and $1957.73 \pm 101.86 \mu \mathrm{g}$ of Trolox/mg DE for DPPH, $\mathrm{ABTS}^{+}$, and superoxide anion scavenging activity, respectively. For FRAP, it was $4181.13 \pm 324.28 \mu \mathrm{g}$ of $\mathrm{FeSO}_{4} / \mathrm{mg} \mathrm{DE}$. This is consistent with the results of previous study [29]. Surprisingly, EtOAc fraction even exhibited stronger antioxidant activity than $\mathrm{Vc}_{\mathrm{C}}$ and BHT, the two most commonly used synthetic antioxidants. In addition, $\mathrm{CE}, \mathrm{CF}$, and $\mathrm{n}-\mathrm{BuOH}$ fractions also possessed better superior antioxidant activities than other fractions and BHT.

Table 2. The antioxidant activities of the $P$. frutescens leaf extract and its fractions.

\begin{tabular}{|c|c|c|c|c|}
\hline Samples & $\begin{array}{l}\text { DPPH Scavenging Activity } \\
\text { ( } \mu \text { g of Trolox/mg DE) }\end{array}$ & $\begin{array}{l}\text { ABTS }^{+} \text {Scavenging Activity } \\
(\mu \mathrm{g} \text { of Trolox/mg DE) }\end{array}$ & $\begin{array}{c}\text { FRAP ( } \mu \text { g of } \\
\left.\text { FeSO }_{4} / \mathrm{mg} \mathrm{DE}\right)\end{array}$ & $\begin{array}{l}\text { Superoxide Anion Scavenging } \\
\text { Activity ( } \mu \mathrm{g} \text { of Trolox/mg DE) }\end{array}$ \\
\hline $\mathrm{CE}$ & $93.82 \pm 1.92^{c}$ & $184.77 \pm 4.71^{\mathrm{e}}$ & $873.79 \pm 30.47^{\mathrm{d}}$ & $440.92 \pm 33.51^{\mathrm{e}}$ \\
\hline PE & $57.32 \pm 5.59 \mathrm{~d}$ & $194.92 \pm 1.37^{\mathrm{e}}$ & $150.24 \pm 14.59^{d}$ & $235.14 \pm 72.32^{f}$ \\
\hline $\mathrm{CF}$ & $562.16 \pm 23.54^{b}$ & $581.70 \pm 10.93^{\mathrm{d}}$ & $1216.90 \pm 71.32^{c}$ & $977.74 \pm 66.28^{c}$ \\
\hline EtOAc & $1006.33 \pm 15.80^{a}$ & $1682.80 \pm 38.49^{a}$ & $4181.13 \pm 324.28^{a}$ & $1957.73 \pm 101.86^{a}$ \\
\hline $\mathrm{n}-\mathrm{BuOH}$ & $94.82 \pm 15.80^{c}$ & $134.46 \pm 27.72 \mathrm{e}$ & $1256.56 \pm 122.21^{\mathrm{c}}$ & $1114.23 \pm 28.19^{c}$ \\
\hline $\mathrm{AQ}$ & $84.43 \pm 1.12^{c, d}$ & $118.37 \pm 2.64^{\mathrm{e}}$ & $353.59 \pm 36.83^{\mathrm{d}}$ & $675.53 \pm 48.04^{\mathrm{d}}$ \\
\hline Vc & $588.68 \pm 10.54^{b}$ & $1479.39 \pm 59.27^{b}$ & $1741.74 \pm 23.20^{b}$ & $1513.92 \pm 21.72^{b}$ \\
\hline BHT & $87.25 \pm 5.84^{c, d}$ & $922.84 \pm 23.12^{c}$ & $784.15 \pm 7.73^{\mathrm{d}}$ & $247.19 \pm 10.72^{\mathrm{f}}$ \\
\hline
\end{tabular}

$\mathrm{CE}=$ crude extract; $\mathrm{PE}=$ petroleum ether fraction; $\mathrm{CF}=$ chloroform fraction; EtOAc $=$ ethyl acetate fraction; $\mathrm{n}-\mathrm{BuOH}=\mathrm{n}$-butanol fraction; $\mathrm{AQ}=$ aqueous phase residue. The different letters represent a significant difference, $p<0.05$.

Pearson correlation analysis (Figure 1) revealed that FRAP and superoxide anion scavenging activity had significant correlations with TPC $(r=0.582$ and $0.469, p<0.05)$, and strong correlations with TFC $(r=0.695$ and $0.612, p<0.01)$. DPPH.scavenging and ABTS. ${ }^{+}$ scavenging activity were not significantly associated with TPC, but highly correlated with TFC ( $r=0.628, p<0.01$, and $r=0.587, p<0.05$, respectively). Results of principal component analysis (PCA) are shown in Figure 2, these four antioxidant activities had almost identical principal component coordinates and relatively close distances to TPC and TFC, and they all could be well differentiated by principal coordinates analysis (PCoA). For different extracts and fractions, the PCA results were also easily distinguishable. Thus, the presence of phenolic and flavonoid compounds are the main contributors to antioxidant activities, 
and the difference between these correlations might be due to the different mechanisms of the antioxidant actions, such as hydrogen atom, single electron transfer, and metal chelation [15].

\section{Correlation Heatmap}

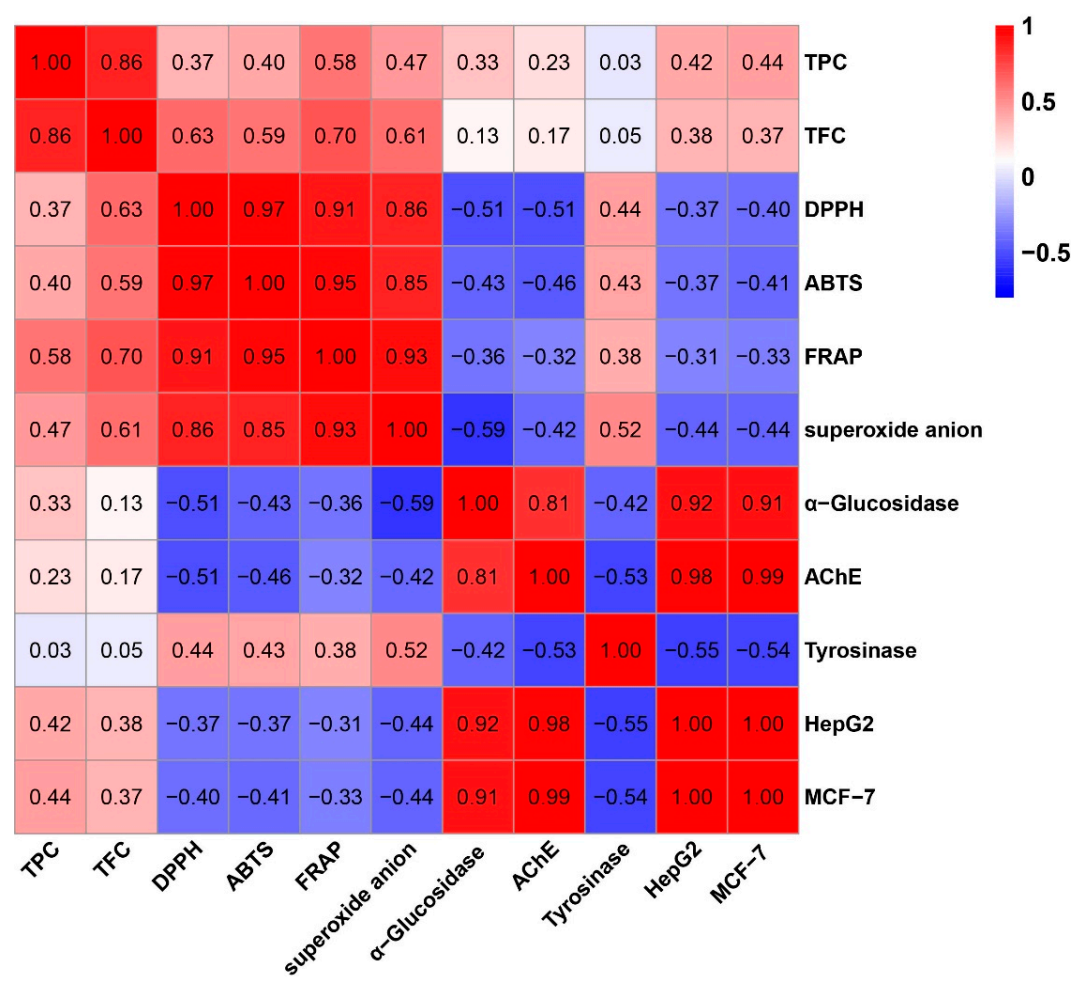

Figure 1. Results of correlational analyses from experiment. The Pearson coefficient $(r)$ is given for each correlation in the corresponding color, and the $p$ value represented as a heatmap ranging from -1 to 1 (red to blue). TPC = total phenolic content; TFC = total flavonoid content; $\mathrm{DPPH}=\mathrm{DPPH}$-scavenging activity; $\mathrm{ABTS}=\mathrm{ABTS}^{+}{ }^{+}$scavenging ability; FRAP $=$ferric reducing antioxidant power; superoxide anion = superoxide anion scavenging activity; $\alpha$-Glucosidase $=$ the $\mathrm{IC}_{50}$ value for $\alpha$-glucosidase inhibitory; $\mathrm{AChE}=$ the $\mathrm{IC}_{50}$ value for acetylcholinesterase inhibitory activity; Tyrosinase $=$ the $\mathrm{IC}_{50}$ value for tyrosinase inhibitory; HepG2 $=$ the $\mathrm{IC}_{50}$ value for inhibition on HepG2 cell proliferation; MCF-7 = the $\mathrm{IC}_{50}$ value for inhibition on MCF-7 cell proliferation.

\subsection{Enzymes Inhibitory Activity}

It is believed that $\alpha$-glucosidase, acetylcholinesterase (AChE), and tyrosinase are important metabolic enzymes relating with oxidative stress, and they are shown to be the key targets of T2DM, Alzheimer's disease (AD), mammalian melanogenesis, and fruit or vegetable enzymatic browning, respectively [30-32]. Natural food and medicinal plants are excellent resources of $\alpha$-glucosidase, $\mathrm{AChE}$, and tyrosinase inhibitors, and have the potential to be novel strategies for the prevention and treatment of these diseases or hazards [32-34].

The inhibition rates of $P$. frutescens leaf extract and its fractions against $\alpha$-glucosidase are shown in Figure 3A, and the $\mathrm{IC}_{50}$ values are presented in Figure 3B. All samples demonstrated certain $\alpha$-glucosidase inhibitory activity in a concentration-dependent manner. Among them, the EtOAc and CF fractions showed the strongest effect on inhibiting $\alpha$-glucosidase, followed by $\mathrm{AQ}, \mathrm{n}-\mathrm{BuOH}, \mathrm{PE}$, and $\mathrm{CE}$. Delightedly, and the $\mathrm{IC}_{50}$ values of the EtOAc, CF, and AQ were 190.03 $\pm 61.29,212.86 \pm 33.98$, and $362.57 \pm 136.99 \mu \mathrm{g} / \mathrm{mL}$, which were superior to control acarbose $(414.46 \pm 42.22 \mu \mathrm{g} / \mathrm{mL})$, respectively. Correlation analyses revealed that $\alpha$-glucosidase inhibitory activity was significantly negatively associ- 
ated with DPPH. scavenging activity and superoxide anion scavenging activity (Figure 1). Considering the postprandial blood glucose levels could be reduced by inhibiting the activity of $\alpha$-glucosidase not only in vitro but also in vivo, the EtOAc fraction was selected for the subsequent animal experiments to evaluate the hypoglycemic effect [35].
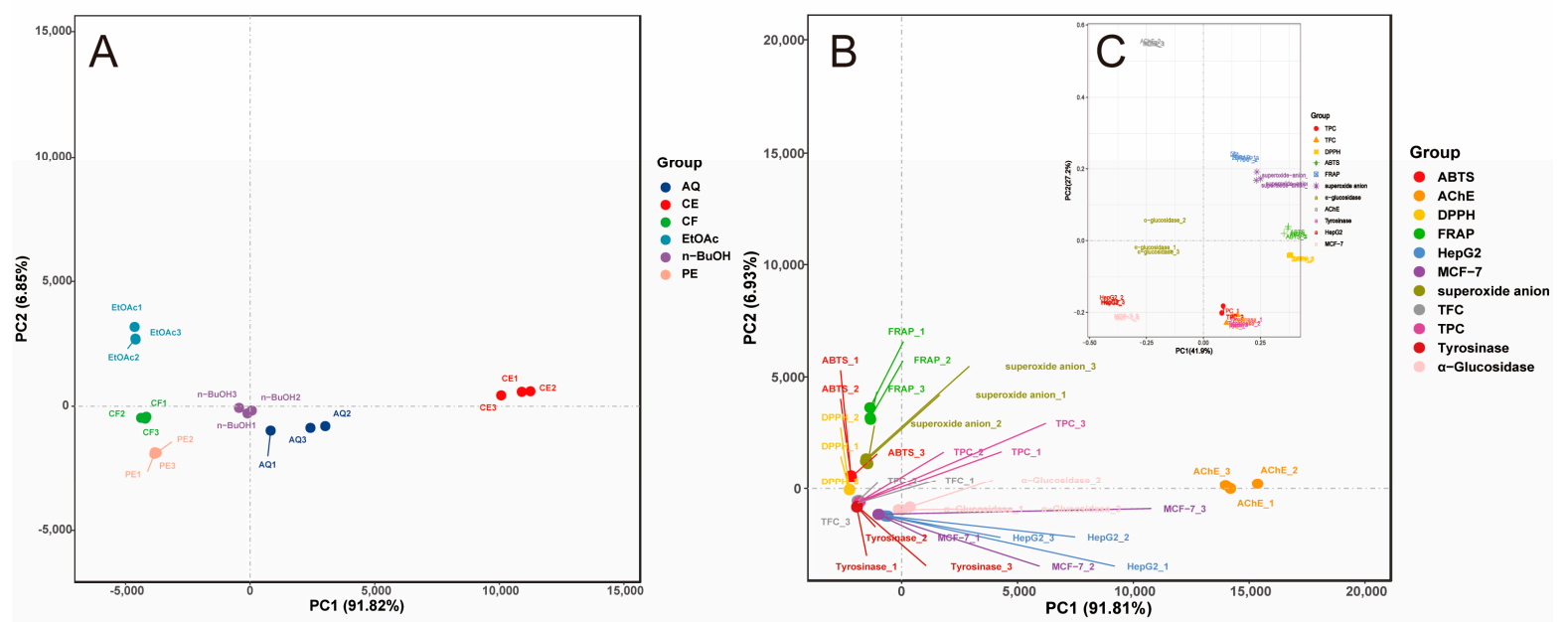

Figure 2. Principal component analysis (PCA) of different samples and indicators. (A) PCA of six P. frutescens leaf extract and fractions; (B) PCA of 11 indicators of active ingredient content and biological activity; (C) principal co-ordinates analysis (PCoA) of 11 indicators of active ingredient content and biological activity. $\mathrm{CE}=$ crude extract; $\mathrm{PE}=$ petroleum ether fraction; $\mathrm{CF}=$ chloroform fraction; EtOAc = ethyl acetate fraction; $\mathrm{n}-\mathrm{BuOH}=\mathrm{n}$-butanol fraction; $\mathrm{AQ}=$ aqueous phase residue; $\mathrm{TPC}=$ total phenolic content; $\mathrm{TFC}=$ total flavonoid content; $\mathrm{DPPH}=\mathrm{DPPH} \cdot$ scavenging activity; $\mathrm{ABTS}=\mathrm{ABTS}+$ scavenging ability; FRAP = ferric reducing antioxidant power; superoxide anion = superoxide anion scavenging activity; $\alpha$ Glucosidase $=$ the $\mathrm{IC}_{50}$ value for $\alpha$-glucosidase inhibitory; $\mathrm{AChE}=$ the $\mathrm{IC}_{50}$ value for acetylcholinesterase inhibitory activity; Tyrosinase $=$ the $\mathrm{IC}_{50}$ value for tyrosinase inhibitory; HepG2 = the $\mathrm{IC}_{50}$ value for inhibition on HepG2 cell proliferation; MCF-7 $=$ the $\mathrm{IC}_{50}$ value for inhibition on MCF-7 cell proliferation.

In Figure 3C,D, similar to the results of the inhibition of $\alpha$-glucosidase activity, $P$. frutescens leaf extract and different fractions showed AChE inhibitory activity in a dosedependent manner. Overall, the EtOAc $\left(\mathrm{IC}_{50}\right.$ value was $\left.267.67 \pm 17.15 \mu \mathrm{g} / \mathrm{mL}\right), \mathrm{CF}$ ( $\mathrm{IC}_{50}$ value was $329.77 \pm 29.62 \mu \mathrm{g} / \mathrm{mL}$ ), and $\mathrm{PE}\left(\mathrm{IC}_{50}\right.$ value was $438.68 \pm 44.11 \mu \mathrm{g} / \mathrm{mL}$ ) fractions performed significantly better inhibition activity than the other fractions (IC 50 value ranging from $4332.67 \pm 233.81$ to $14924.08 \pm 605.75 \mu \mathrm{g} / \mathrm{mL}$ ). According to the results of correlation analysis, AChE inhibitory activity was significantly negatively associated with DPPH. scavenging activity $(r=-0.51, p<0.05)$, and strong correlation with $\alpha$ glucosidase inhibitory activity $(r=0.81, p<0.01)$, while correlations with TPC, TFC, FRAP, and superoxide anion scavenging activity were not significant.

The results shown in Figure 3E,F indicated that $\mathrm{CE}, \mathrm{AQ}$, and EtOAc fractions had activity against tyrosinase with the $\mathrm{IC}_{50}$ value of $328.04 \pm 24.16,339.61 \pm 19.74$, and $354.84 \pm 25.30 \mu \mathrm{g} / \mathrm{mL}$, whereas no inhibitory activity was detected for other fractions.

According to Figure $2 \mathrm{~B}, \mathrm{C}$, although $\alpha$-glucosidase, $\mathrm{AChE}$, and tyrosinase inhibitory activities did not yield a complete group separation on the PCA2 axes, they clustered far from each other along the PCA1 axis. Of which, $\alpha$-glucosidase and AChE inhibitory activities were separated from TPC, TFC, and showed a substantial distance with four antioxidant activities. These results suggested that the bioactivities might be interrelated but not the main influence factors for each other, which could be due to the multicomponent and multitarget characteristics of $P$. frutescens leaf extract. 

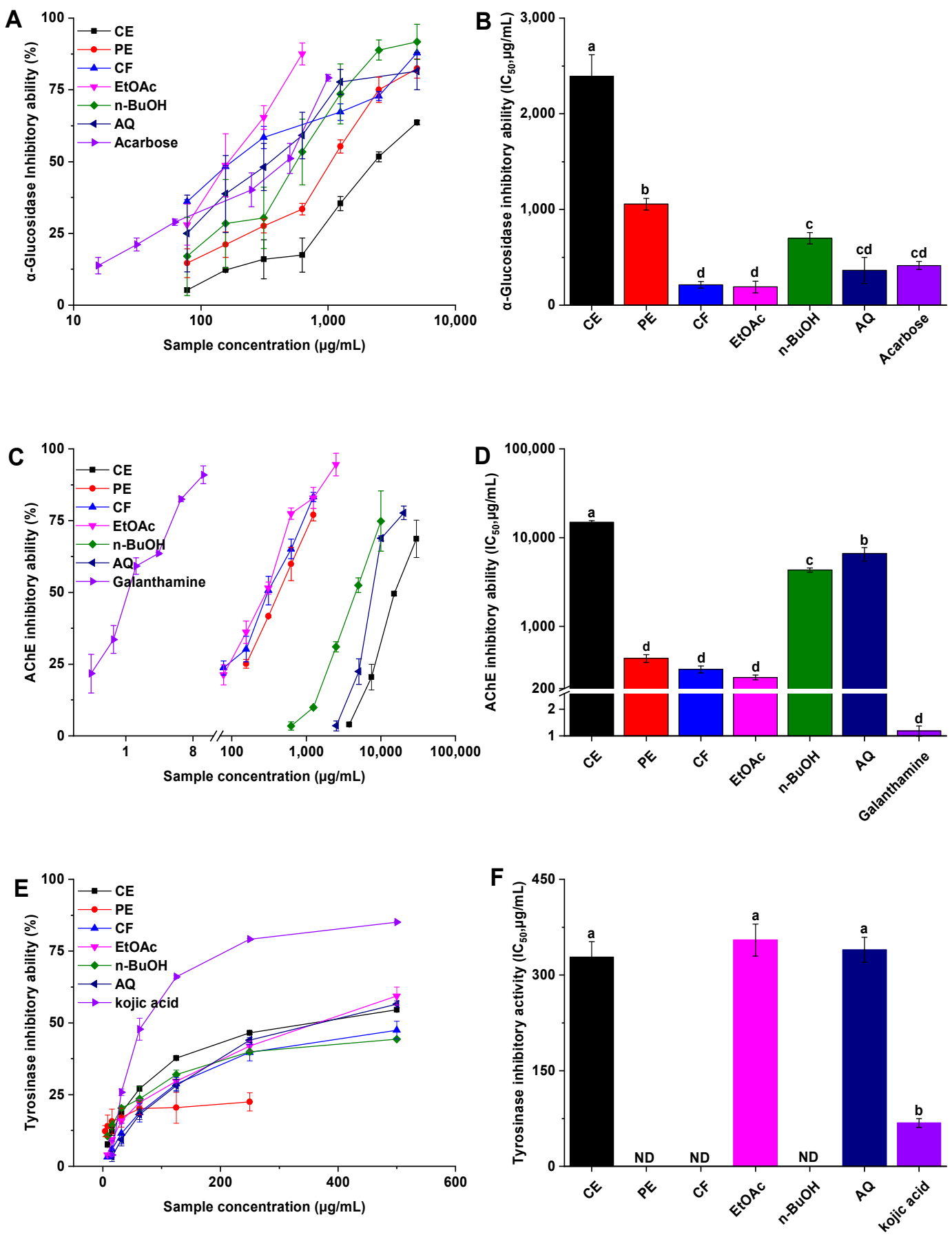

Figure 3. The enzymes inhibitory activities of the $P$. frutescens leaf extract and its fractions. (A) The inhibition ratio of $\alpha$-glucosidase incubated with different concentrations of samples; (B) the $\mathrm{IC}_{50}$ values of different samples for $\alpha$-glucosidase inhibition; $(C)$ the inhibition ratio of acetylcholinesterase incubated with different concentrations of samples; $(\mathbf{D})$ the $\mathrm{IC}_{50}$ values of different samples for acetylcholinesterase inhibition; (E) the inhibition ratio of tyrosinase incubated with different concentrations of samples; $(\mathrm{F})$ the $\mathrm{IC}_{50}$ values of different samples for tyrosinase inhibition. $\mathrm{ND}=$ not detected; $\mathrm{CE}=\mathrm{crude}$ extract; $\mathrm{PE}=$ petroleum ether fraction; $\mathrm{CF}=$ chloroform fraction; EtOAc $=$ ethyl acetate fraction; $\mathrm{n}-\mathrm{BuOH}=\mathrm{n}-\mathrm{butanol}$ fraction; $\mathrm{AQ}=$ aqueous phase residue. Bars with different letters indicate a significant difference $(p<0.05)$.

\subsection{Anticancer Activity}

Recent studies reported that diabetes could contribute to the development of cancer via inflammation, and thus has been identified as a risk factor for cancer and cancer-related mortality [36,37]. Malignant tumors such as hepatocellular carcinoma and breast cancer 
are important causes of human death, and a significant link between them and diabetes has been evidenced [38-41].

In this study, the inhibition of the P. frutescens leaf extract and its fractions on HepG2 and MCF-7 cell growth were performed to evaluate its anticancer activities. From Figure 4, only EtOAc, PE, n-BuOH, and CE fractions showed inhibitory effects on HepG2 and MCF-7 cell proliferation in a dose-dependent manner. The inhibition activity of these fractions on HepG2 cell are shown in Figure 4B, and the $\mathrm{IC}_{50}$ values of EtOAc, $\mathrm{PE}, \mathrm{n}-\mathrm{BuOH}$, and $\mathrm{CE}$ were $13.43 \pm 0.10,48.07 \pm 5.27,186.43 \pm 2.39$, and $1835.73 \pm 71.05 \mu \mathrm{g} / \mathrm{mL}$, respectively, while it was $35.53 \pm 3.89 \mu \mathrm{g} / \mathrm{mL}$ for the control cisplatin. No significant difference was found between EtOAc and PE $(p>0.05)$. According to the similar results presented in Figure 4D, EtOAc, PE, n-BuOH, CE, and cisplatin inhibited MCF-7 cell with $\mathrm{IC}_{50}$ values of $37.92 \pm 6.82$, $70 \pm 19.74,271.26 \pm 6.80,1439.89 \pm 27.70$, and $33.03 \pm 7.49 \mu \mathrm{g} / \mathrm{mL}$, respectively. Similarly, there was no significant difference between EtOAc, PE, and cisplatin.
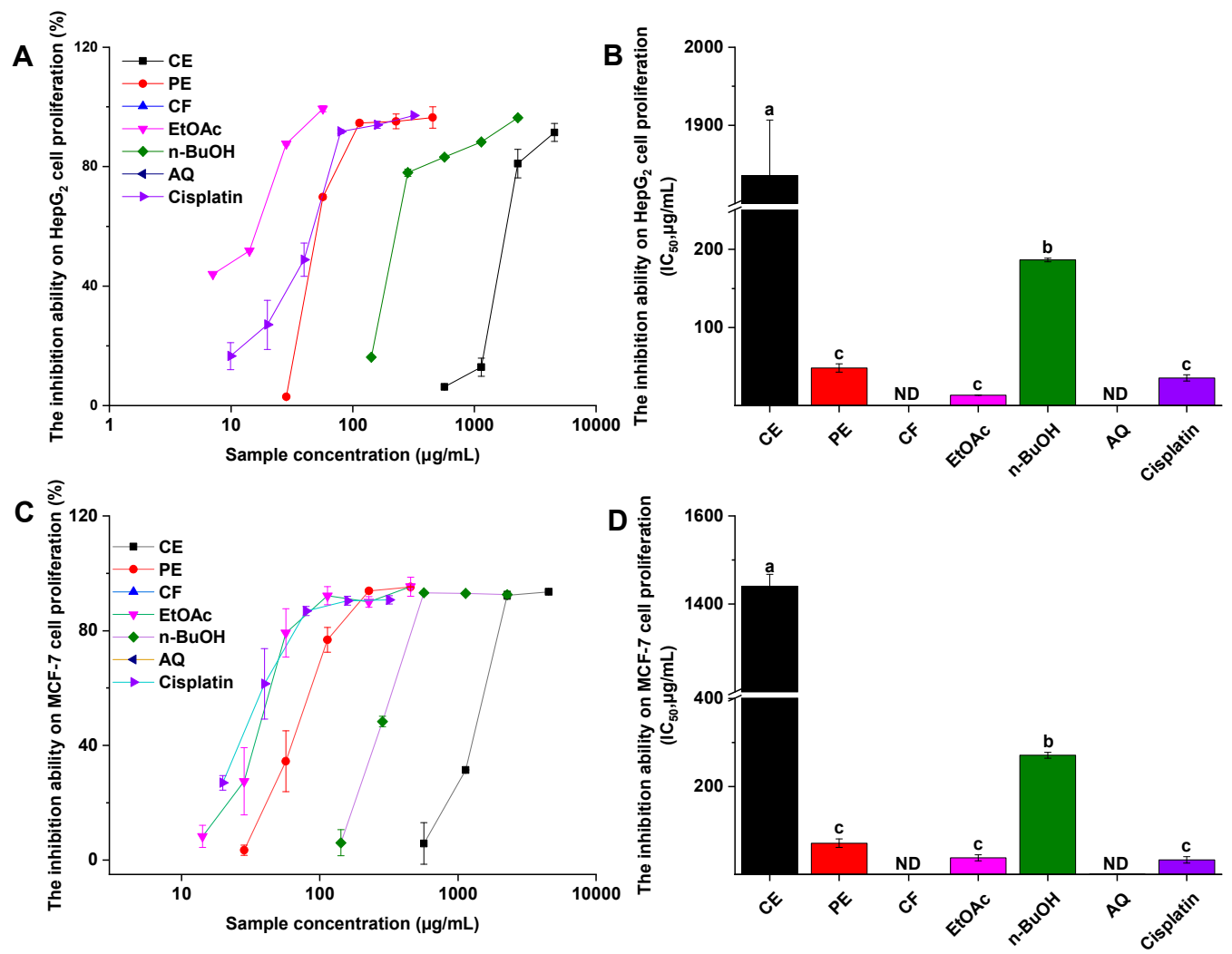

Figure 4. The cell proliferation inhibitory activity of the $P$. frutescens leave extract and its fractions. (A) The inhibition ratio of HepG2 cell proliferation incubated with different concentrations of samples; (B) the $\mathrm{IC}_{50}$ values of different samples for HepG2 cell proliferation inhibition; (C) the inhibition ratio of MCF-7 cell proliferation incubated with different concentrations of samples; $(\mathrm{D})$ the $\mathrm{IC}_{50}$ values of different samples for MCF-7 cell proliferation inhibition. $\mathrm{ND}=$ not detected; $\mathrm{CE}=$ crude extract; $\mathrm{PE}=$ petroleum ether fraction; $\mathrm{CF}=$ chloroform fraction; EtOAc = ethyl acetate fraction; $\mathrm{n}-\mathrm{BuOH}=\mathrm{n}$-butanol fraction; $\mathrm{AQ}=$ aqueous phase residue. Bars with different letters indicate a significant difference $(p<0.05)$.

From Figure 1, for the $P$. frutescens leaf extract and its fractions, their capacities to inhibit HepG2 cell proliferation were significantly correlated with their abilities to inhibit MCF-7 cell $(r=1.00, p<0.01), \alpha$-glucosidase $(r=0.92, p<0.01)$, and AChE $(r=0.98, p<0.01)$. Likewise, the MCF-7 cell proliferation inhibitory ability was significantly associated with $\alpha$-glucosidase inhibitory activity $(r=0.91, p<0.01)$ and AChE inhibitory activity $(r=0.99$, $p<0.01$ ). In light of the findings from PCA results (Figure 2), TPC, TFC, $\alpha$-glucosidase and AChE inhibitory activity, and anticancer activity demonstrated closer relationship between 
each other along the PC2 axis. These combined findings suggested that $\alpha$-glucosidase and AChE inhibitory activity, and anticancer activity, may be due to the combined effects of the complex ingredients in P. frutescens leaves, rather than a single component.

\subsection{HPLC-DAD Analyses}

As in the preceding sections, the EtOAc fraction presented high active ingredient content and the strongest biological activities in all fractions, thus it was selected for further analyses. In this study, the components of the EtOAc fraction were analyzed by HPLCDAD. Five phenolic acids and nine flavonoids were identified and quantified, and detailed results are displayed in Table 3. Of these, the content of luteolin, rosmarinic acid, rutin, and catechin were $254.56 \pm 3.74,163.88 \pm 2.53,97.56 \pm 11.09$, and $94.70 \pm 1.35 \mu \mathrm{g} / \mathrm{mg}$, which were the dominant components, respectively. Additionally, gallic acid, chlorogenic acid, L-epicatechin, dihydromyricetin, ferulic acid, (-)-epicatechin gallate, baicalin, apigenin, hesperetin, and baicalein were also detected. Many previous studies described the presence of these compounds in P. frutescens leaves crude extract and their biological activities, such as antioxidant, $\alpha$-glucosidase inhibition, anticancer, and hypoglycemic activity $[28,29,42,43]$.

Table 3. The HPLC analysis of the ethyl acetate fraction of $P$. frutescens leaves.

\begin{tabular}{ccccc}
\hline Retention Time (min) & Compounds & Types of Compounds & Measuring Wavelength (nm) & Content ( $\mu$ g/mg) \\
\hline 9.99 & Gallic acid & Phenolic acids & 280 & $11.13 \pm 0.23^{\mathrm{e}, \mathrm{f}}$ \\
16.78 & Catechin & Flavonoids & 280 & $94.70 \pm 1.35^{\mathrm{c}}$ \\
22.40 & Chlorogenic acid & Phenolic acids & 310 & $14.09 \pm 2.11^{\mathrm{e}}$ \\
23.46 & L-Epicatechin & Phenolic acids & 280 & $14.41 \pm 0.26^{\mathrm{e}}$ \\
27.22 & Dihydromyricetin & Flavonoids & 280 & $3.71 \pm 0.41^{\mathrm{f}}$ \\
30.21 & Rutin & Flavonoids & 360 & $97.56 \pm 11.09^{\mathrm{c}}$ \\
36.71 & Ferulic acid & Phenolic acids & 340 & $3.78 \pm 0.06^{\mathrm{f}}$ \\
39.51 & (-)-Epicatechin gallate & Flavonoids & 280 & $2.11^{\mathrm{f}} \pm 0.69^{\mathrm{f}}$ \\
40.25 & Rosmarinic acid & Phenolic acids & 310 & $163.88 \pm 2.53^{\mathrm{b}}$ \\
43.86 & Baicalin & Flavonoids & 310 & $53.67 \pm 0.81^{\mathrm{d}}$ \\
47.02 & Luteolin & Flavonoids & 360 & $254.56 \pm 3.74^{\mathrm{a}}$ \\
56.38 & Apigenin & Flavonoids & 310 & $7.32 \pm 1.12^{\text {ef }}$ \\
57.14 & Hesperetin & Flavonoids & 340 & $9.98 \pm 1.56^{\mathrm{ef}}$ \\
62.40 & Baicalein & Flavonoids & $9.40 \pm 0.96^{\mathrm{ef}}$ \\
\hline
\end{tabular}

The different letters represent a significant difference, $p<0.05$.

\subsection{Antidiabetic Activity}

\subsubsection{Physical Appearance and Biochemical Parameters}

As shown in Figure 5, STZ-induced diabetic rats showed symptoms of mental depression, lusterless body complexion, and slow response. In addition, diabetic groups exhibited increasing blood glucose levels, food intake, water intake, and decreased bodyweight, which were the important hallmarks of T2DM (Figure 6) [44]. After 4 weeks of administration with the EtOAc fraction of $P$. frutescens leaves, these appearances were significantly improved. Treated rats had soft and shiny hair, and were shown to be significantly more sensitive to the reaction (Figure 5).

There were no statistically significant differences in the body weight between HFD, HFD-ME, HFD-HE, and HFD-A groups, but showed a significant reduction when compared with the ND group at $p<0.05$ (Figure 6A). From Figure 6, the consumption of EtOAc fraction and acarbose reduced food intake, water intake, and postprandial glucose concentrations. Surprisingly, the ameliorative potential of high-dose EtOAc fraction was equivalent to or better than that of acarbose, a well-known commercial drug for diabetes. 


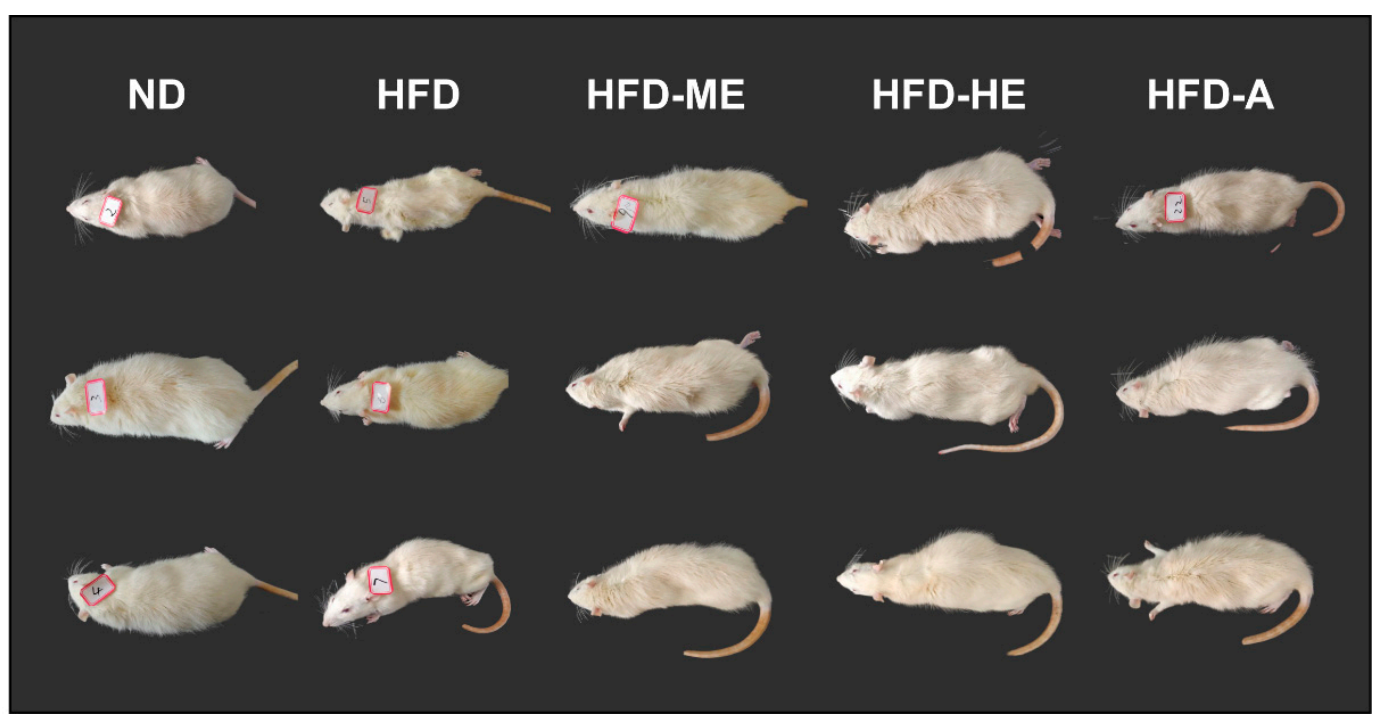

Figure 5. Effect of the ethyl acetate fraction of $P$. frutescens leaves on the appearance of STZ-induced diabetic rats. ND $=$ normal diet group; HFD = high-fat diet group; HFD-ME = high-fat diet with medium dose extracts group; HFD-HE = high-fat diet with high dose extracts group; HFD-A = high-fat diet with acarbose group.



A

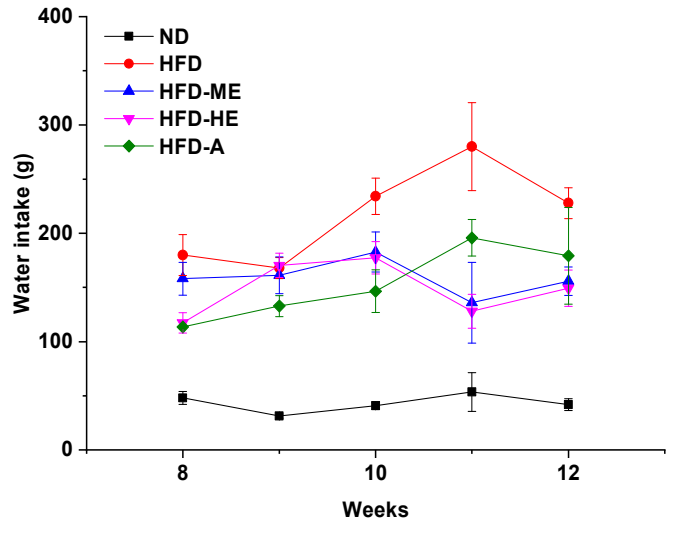

C

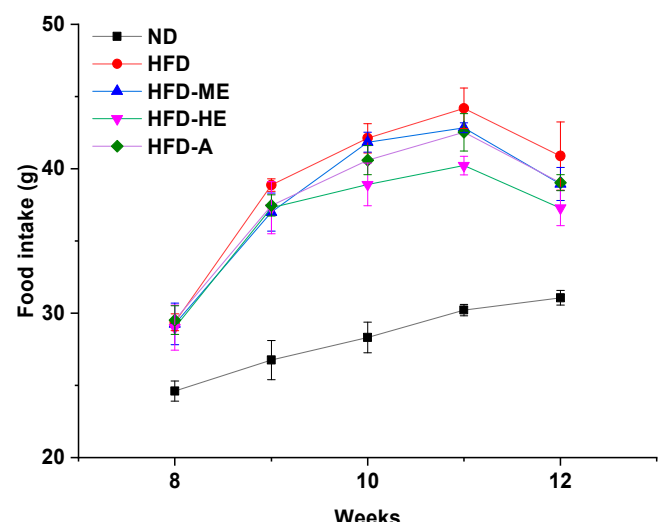

B

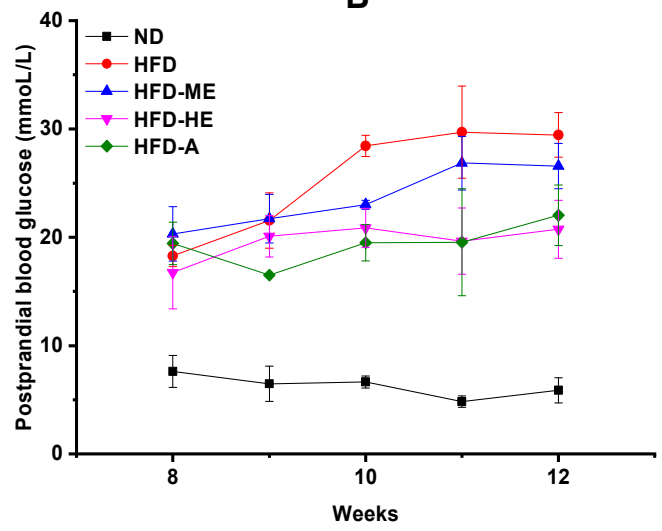

D

Figure 6. Effect of the ethyl acetate fraction of P. frutescens leaves on the biochemical parameters of STZ-induced diabetic rats. (A) Body weight; (B) food intake; (C) water intake; (D) postprandial blood glucose. ND = normal diet group; HFD = high-fat diet group; HFD-ME = high-fat diet with medium dose extracts group; HFD-HE = high-fat diet with high dose extracts group; HFD-A = high-fat diet with acarbose group. 
Dyslipidemia commonly occurs in metabolic syndrome disease patients such as diabetics, therefore, the beneficial effects on glucose metabolism were also associated with an improvement in lipid profile $[45,46]$. To determine the effect of EtOAc fraction on dyslipidemia, the lipid levels in the rat serum were measured, and the results are shown in Table 4. The HFD group showed a significant increase in TC, TG, and LDL-C, while a significant decrease in HDL-C compared to the NC group was seen. Feeding of EtOAc fraction significantly reduced the TC, TG, and LDL-C levels, and increased the HDL-C levels of HFD-fed rats $(p<0.05)$; here, the high-dose treatment group was significantly superior to the positive control acarbose group $(p<0.05)$.

Table 4. Effect of the ethyl acetate fraction of P. frutescens leaves on the blood lipid parameters of STZ-induced diabetic rats.

\begin{tabular}{ccccc}
\hline Groups & TC & TG & HDL-C & LDL-C \\
\hline NC & $1.36 \pm 0.05^{\mathrm{c}}$ & $0.81 \pm 0.06^{\mathrm{e}}$ & $1.16 \pm 0.03^{\mathrm{a}}$ & $0.21 \pm 0.03^{\mathrm{c}}$ \\
HFD & $2.40 \pm 0.03^{\mathrm{a}}$ & $1.75 \pm 0.13^{\mathrm{a}}$ & $0.80 \pm 0.07^{\mathrm{c}}$ & $0.55 \pm 0.10^{\mathrm{a}}$ \\
HFD-ME & $1.92 \pm 0.11^{\mathrm{b}}$ & $1.52 \pm 0.09^{\mathrm{b}}$ & $0.91 \pm 0.07^{\mathrm{bc}}$ & $0.38 \pm 0.04^{\mathrm{b}}$ \\
HFD-HE & $1.50 \pm 0.08^{\mathrm{c}}$ & $1.05 \pm 0.07^{\mathrm{d}}$ & $1.14 \pm 0.07^{\mathrm{a}}$ & $0.26 \pm 0.03^{\mathrm{c}}$ \\
HFD-A & $1.76 \pm 0.14^{\mathrm{b}}$ & $1.35 \pm 0.06^{\mathrm{c}}$ & $1.08 \pm 0.14^{\mathrm{ab}}$ & $0.26 \pm 0.03^{\mathrm{b}}$ \\
\hline
\end{tabular}

TC = total cholesterol; TG = triglyceride; HDL-C = high-density lipoprotein cholesterol; LDL-C = low-density lipoprotein cholesterol; ND = normal diet group; HFD = high-fat diet group; HFD-ME = high-fat diet with medium dose extracts group; HFD-HE = high-fat diet with high dose extracts group; HFD-A = high-fat diet with acarbose group. The different letters represent a significant difference, $p<0.05$.

\subsubsection{Histopathology Changes of the Liver and Intestinal}

The liver and intestinal were the main tissue involved in energy and glucose metabolism $[47,48]$. Histological analysis of the liver and intestinal tissues by H\&E staining are shown in Figure 7A, and the microscope pictures show the transverse sections of tissues. The hepatocytes of the ND group had a clear morphology, round or oval cell clusters, centrally located nuclei, and clear boundaries, while that of diabetic rats showed marked vacuolization, reducing nuclei size, and disordered liver structure. The rats treated with EtOAc fraction and acarbose showed improvement in the histological abnormalities with an obvious increase in the number of hepatocytes and improved shape. The organization of the intestinal tissue of rats in the ND group was normal, and the mucosal villous structure was neatly arranged with a clear structure, while the intestinal lesions of diabetic rats were obvious, and some intestinal villi were necrotic and shed or even disappeared. Average villus length was increased at varying degrees throughout the intestine in EtOAc fraction and acarbose-treated groups compared with the ND group.

Glycogen is the polyglucosan storage and PAS staining is used as a qualitative indicator of glycogen accumulation and cell damage [49]. Figure 7 indicated that the ND group showed rich glycogen storage in the liver and intestinal tissues, while the ND group showed a decrease in the accumulation of glycogen, which might account for the diabetes-induced reductions in the capability of synthesizing and accumulating glycogen [50]. After 4 weeks of treatments with the EtOAc fraction, the glycogen accumulation in the liver and intestinal was effectively increased. Compared to acarbose, the high dose of the EtOAc fraction showed a stronger ability to promote glycogen synthesis, and then controlled hyperglycemia. 


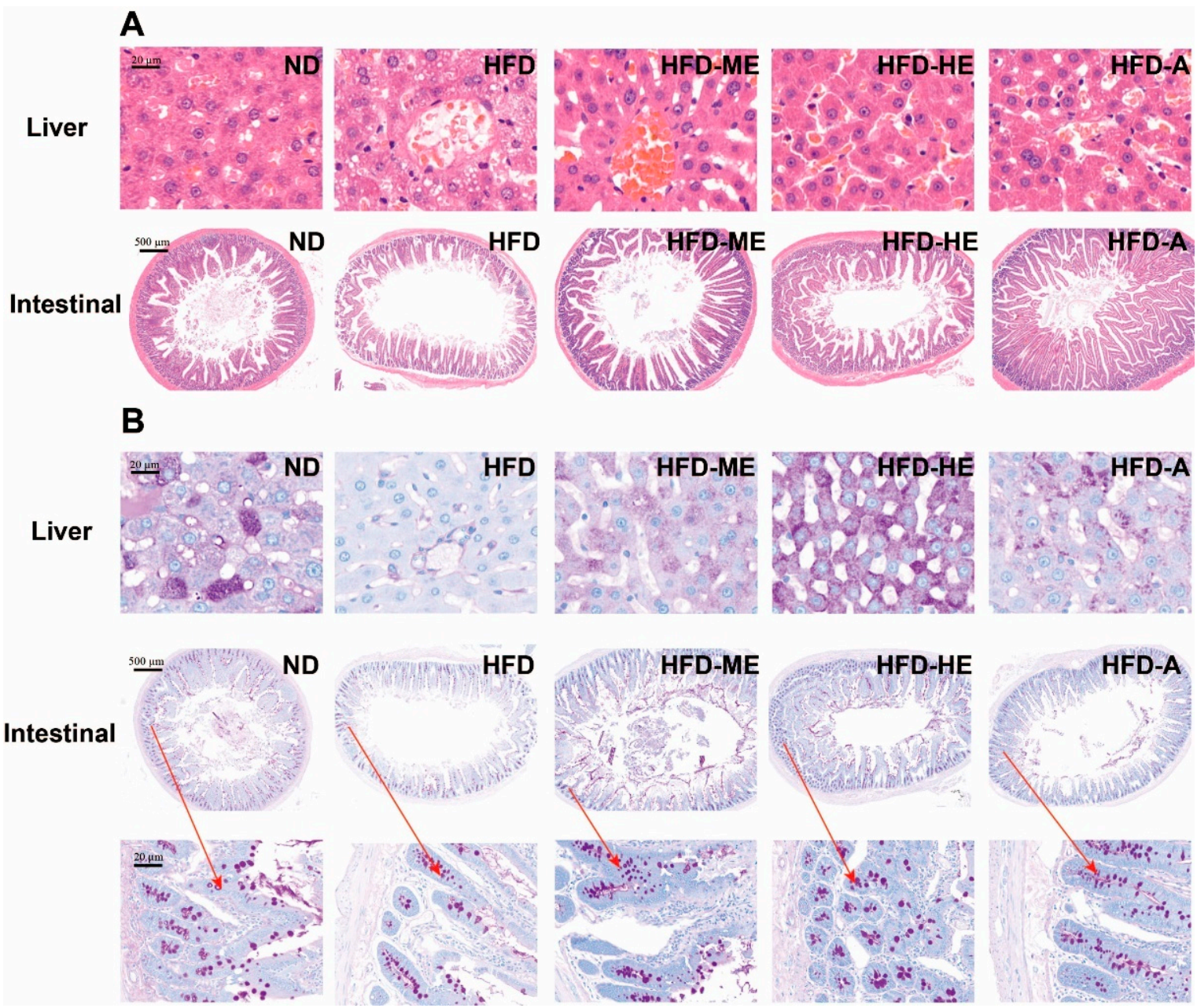

Figure 7. Effect of the ethyl acetate fraction of $P$. frutescens leaves on the histopathology of STZ-induced diabetic rats. (A) H\&E staining; (B) PAS staining. ND = normal diet group; HFD = high-fat diet group; HFD-ME = high-fat diet with medium dose extracts group; HFD-HE = high-fat diet with high dose extracts group; HFD-A = high-fat diet with acarbose group.

\section{Discussion}

It is known that there are close relationships between oxidative stress and the development of various diseases such as diabetes mellitus, cancer, neurodegenerative disease, and metabolic syndrome [51,52]. Many active ingredients in traditional food and medicinal plant have shown excellent effects in the prevention of oxidative stress-induced health risks, and this phenomenon has become a key focus of the current study [53]. Because of the complexity of these illnesses, and the multi-component system in food/plants, most researches are limited to the impacts of the entire extract on one/few indexes of oxidative stress and its corresponding metabolic diseases, there are relatively fewer studies on the effects of the subdivided components of these food/plants on multiple oxidative stress-related diseases.

As an important medicine food plant in South East Asia, P. frutescens has been shown to have rich biochemical compounds and many biological activities including the antidiabetic activity in vitro, but few studies have been conducted on its hypoglycemic potential in vivo. In this study, P. frutescens leaves were extracted using methanol solution and isolated by liquid-liquid partitioning, and the functional activities and chemical compositions of different polar fractions were investigated.

Results showed that the EtOAc fraction possessed higher total phenolic content and the highest total flavonoid content. It also showed the strongest DPPH radical, ABTS radical, superoxide anion scavenging activity, and ferric reducing antioxidant power, even stronger than $\mathrm{Vc}_{\mathrm{c}}$ and BHT. The $\alpha$-glucosidase inhibition potency of each fraction was evaluated, 
and the EtOAc fraction displayed the most potent $\alpha$-glucosidase inhibitory activity twice higher than acarbose, and the same trend was reflected in the AChE inhibition experiment. Additionally, the EtOAc fraction has the highest inhibitory effect on MCF-7 and HepG2 cell proliferation. Considering that there was a strong correlation with each other between these in vitro activities and oxidative stress-related diseases, the EtOAc fraction was used for HPLC analysis and the subsequent animal experiment.

The HPLC-DAD analysis of the EtOAc fraction detected five phenolic acids and nine flavonoids, and luteolin, rosmarinic acid, rutin, and catechin were the dominant components of the fraction. To assess the hypoglycemic effect of the EtOAc fraction, the T2DM SD rat model induced by high-fat diet/low-dose STZ was established, and the physical appearance, biochemical parameters, and histopathology changes were evaluated. Results showed that the EtOAc fraction could significantly decrease the serum glucose level, food and water intake, and increased the body weight of diabetic rats, and improved their serum levels of TC, TG, HDL-C, and LDL-C.

Histopathological analysis of the livers and intestinal tissue revealed EtOAc fraction treatments could effectively ameliorate diabetes-related pathophysiology conditions in livers and intestinal tissue, such as tissue injury and villus rupture. PAS staining analysis showed that the intake of EtOAc fraction could increase glycogen accumulation in the livers and intestine, and thereby avoid the entrance of glucose into the bloodstream, which in turn caused hyperglycemia and diabetes.

Taken together, the EtOAc fraction of $P$. frutescens leaves exhibited excellent antioxidant activity, $\alpha$-glucosidase, acetylcholinesterase, tyrosinase inhibition activity, anticancer activity, and in vivo hypoglycemic activity.

\section{Conclusions}

In this study, P. frutescens leaves showed promising hypoglycemic activity in vitro and in vivo, which could be exploited as a source of natural antidiabetic. To the best of our knowledge, this is the first comparative study of the biological activities of different solvent extracts of $P$. frutescens leaves, and demonstrate the beneficial effect of its EtOAc fraction in hypoglycemic actions. Further research is needed to investigate the underlying mechanisms of the hypoglycemic effects by researching the transcriptomics, metabolomics, and intestinal microbiota, etc.

Author Contributions: Methodology, Z.W. and X.X.; validation, Z.W. and H.C.; formal analysis, K.W.K.; data curation, X.X.; writing—original draft preparation, Z.W.; writing—review and editing, K.W.K., H.C., and L.Z.; supervision, X.X.; project administration, Z.T.; funding acquisition, Z.T. All authors have read and agreed to the published version of the manuscript.

Funding: This research was funded by the Key R \& D projects in Jiangxi Province (grant number 20181BCD40006), the Key youth projects in Jiangxi Province (grant number 20192ACB21011), and Guangxi Key Laboratory of Fruits and Vegetables Storage-Processing Technology (grant number GXKLFV003).

Institutional Review Board Statement: The study was conducted according to the guidelines of the Declaration of Helsinki, and approved by the Academic Committee of Southwest Forestry University (ethical approval number SWFU-2018003).

Informed Consent Statement: Not applicable.

Data Availability Statement: The remaining data are available on request from the corresponding author.

Acknowledgments: The authors thank the support of the College of Life Sciences, Jiangxi Normal University, and College of Life Sciences, Southwest Forestry University.

Conflicts of Interest: The authors declare no conflict of interest. 


\section{References}

1. Yaribeygi, H.; Sathyapalan, T.; Atkin, S.L.; Sahebkar, A. Molecular Mechanisms Linking Oxidative Stress and Diabetes Mellitus. Oxid. Med. Cell. Longev. 2020, 2020, 8609213. [CrossRef] [PubMed]

2. Asmat, U.; Abad, K.; Ismail, K. Diabetes mellitus and oxidative stress-A concise review. Saudi Pharm. J. 2016, $24,547-553$. [CrossRef] [PubMed]

3. Incalza, M.A.; D’Oria, R.; Natalicchio, A.; Perrini, S.; Laviola, L.; Giorgino, F. Oxidative stress and reactive oxygen species in endothelial dysfunction associated with cardiovascular and metabolic diseases. Vasc. Pharm. 2018, 100, 1-19. [CrossRef] [PubMed]

4. Blanka, K.; Kamil, K.; Petra, M. Global View on Alzheimer's Disease and Diabetes Mellitus: Threats, Risks and Treatment Alzheimer's Disease and Diabetes Mellitus. Curr. Alzheimer Res. 2018, 15, 1277-1282. [CrossRef]

5. Umanath, K.; Lewis, J.B. Update on Diabetic Nephropathy: Core Curriculum 2018. Am. J. Kidney Dis. 2018, 71, 884-895. [CrossRef]

6. Rajendran, P.; Nandakumar, N.; Rengarajan, T.; Palaniswami, R.; Gnanadhas, E.N.; Lakshminarasaiah, U.; Gopas, J.; Nishigaki, I. Antioxidants and human diseases. Clin. Chim. Acta 2014, 436, 332-347. [CrossRef] [PubMed]

7. Mannino, G.; Di Stefano, V.; Lauria, A.; Pitonzo, R.; Gentile, C. Vaccinium macrocarpon (Cranberry)-Based Dietary Supplements: Variation in Mass Uniformity, Proanthocyanidin Dosage and Anthocyanin Profile Demonstrates Quality Control Standard Needed. Nutrients 2020, 12, 992. [CrossRef]

8. Hys, K. Identification of the Reasons Why Individual Consumers Purchase Dietary Supplements. In Perspectives on Consumer Behaviour: Theoretical Aspects and Practical Applications; Sroka, W., Ed.; Springer: Cham, Switzerland, 2020; pp. 193-209. [CrossRef]

9. Hamulka, J.; Jeruszka-Bielak, M.; Górnicka, M.; Drywień, M.E.; Zielinska-Pukos, M.A. Dietary Supplements during COVID-19 Outbreak. Results of Google Trends Analysis Supported by PLifeCOVID-19 Online Studies. Nutrients 2021, 13, 54. [CrossRef]

10. Sfodera, F.; Mattiacci, A.; Nosi, C.; Mingo, I. Social networks feed the food supplements shadow market. Br. Food J. 2020, 122, 1531-1548. [CrossRef]

11. Ghimire, B.K.; Yoo, J.H.; Yu, C.Y.; Kim, S.H.; Chung, I.M. Profiling volatile and phenolic compound composition and characterization of the morphological and biological activities of Perilla frutescence Britton var. Japonica accessions. Acta Physiol. Plant. 2019, 41, 108. [CrossRef]

12. Lee, Y.; Lee, J.; Ju, J. Perilla frutescens Britton var. frutescens leaves attenuate dextran sulfate sodium-induced acute colitis in mice and lipopolysaccharide-stimulated angiogenic processes in human umbilical vein endothelial cells. Food Sci. Biotechnol. 2020, 29, 131-140. [CrossRef] [PubMed]

13. Hashimoto, M.; Tanabe, Y.; Hossain, S.; Matsuzaki, K.; Ohno, M.; Kato, S.; Katakura, M.; Shido, O. Intake of Alpha-Linolenic Acid-Rich Perilla frutescens Leaf Powder Dec reases Home Blood Pressure and Serum Oxidized Low-Density Lipoprotein in Japanese Adults. Molecules 2020, 25, 2099. [CrossRef] [PubMed]

14. Lee, J.E.; Kim, N.; Yeo, J.Y.; Seo, D.G.; Kim, S.; Lee, J.S.; Hwang, K.W.; Park, S.Y. Anti-amyloidogenic effects of asarone derivatives from Perilla frutescens leaves against beta-amyloid aggregation and nitric oxide production. Molecules 2019, 24, 4297. [CrossRef] [PubMed]

15. Wang, Z.-X.; Lin, Q.-Q.; Tu, Z.-C.; Zhang, L. The influence of in vitro gastrointestinal digestion on the Perilla frutescens leaf extract: Changes in the active compounds and bioactivities. J. Food Biochem. 2020, 44, e13530. [CrossRef] [PubMed]

16. Zhu, F.; Asada, T.; Sato, A.; Koi, Y.; Nishiwaki, H.; Tamura, H. Rosmarinic acid extract for antioxidant, antiallergic, and $\alpha-$ glucosidase inhibitory activities, isolated by supramolecular technique and solvent extraction from Perilla leaves. J. Agric. Food Chem. 2014, 62, 885-892. [CrossRef] [PubMed]

17. Ha, T.J.; Lee, J.H.; Lee, M.H.; Lee, B.W.; Kwon, H.S.; Park, C.H.; Shim, K.B.; Kim, H.T.; Baek, I.Y.; Jang, D.S. Isolation and identification of phenolic compounds from the seeds of Perilla frutescens (L.) and their inhibitory activities against alphaglucosidase and aldose reductase. Food Chem. 2012, 135, 1397-1403. [CrossRef]

18. Martins, I.M.; Roberto, B.S.; Blumberg, J.B.; Chen, C.Y.O.; Macedo, G.A. Enzymatic biotransformation of polyphenolics increases antioxidant activity of red and white grape pomace. Food Res. Int. 2016, 89, 533-539. [CrossRef]

19. Thavamoney, N.; Sivanadian, L.; Tee, L.H.; Khoo, H.E.; Prasad, K.N.; Kong, K.W. Extraction and recovery of phytochemical components and antioxidative properties in fruit parts of Dacryodes rostrata influenced by different solvents. J. Food Sci. Technol. 2018, 55, 2523-2532. [CrossRef]

20. Huang, R.; Wu, W.; Shen, S.; Fan, J.; Chang, Y.; Chen, S.; Ye, X. Evaluation of colorimetric methods for quantification of citrus flavonoids to avoid misuse. Anal. Methods 2018, 10, 2575-2587. [CrossRef]

21. Chan, K.W.; Iqbal, S.; Khong, N.M.H.; Ooi, D.-J.; Ismail, M. Antioxidant activity of phenolics-saponins rich fraction prepared from defatted kenaf seed meal. LWT Food Sci. Technol. 2014, 56, 181-186. [CrossRef]

22. Sarega, N.; Imam, M.U.; Ooi, D.-J.; Chan, K.W.; Md Esa, N.; Zawawi, N.; Ismail, M. Phenolic Rich Extract from Clinacanthus nutans Attenuates Hyperlipidemia-Associated Oxidative Stress in Rats. Oxid. Med. Cell. Longev. 2016, 2016, 4137908. [CrossRef] [PubMed]

23. Zhang, L.; Tu, Z.C.; Xie, X.; Lu, Y.; Wang, Z.X.; Wang, H.; Sha, X.M. Antihyperglycemic, antioxidant activities of two Acer palmatum cultivars, and identification of phenolics profile by UPLC-QTOF-MS/MS: New natural sources of functional constituents. Ind. Crops Prod. 2016, 89, 522-532. [CrossRef]

24. Zhou, G.; Chen, Y.; Liu, S.; Yao, X.; Wang, Y. In vitro and in vivo hepatoprotective and antioxidant activity of ethanolic extract from Meconopsis integrifolia (Maxim.) Franch. J. Ethnopharmacol. 2013, 148, 664-670. [CrossRef] [PubMed] 
25. Moyo, M.; Aremu, A.O.; Chukwujekwu, J.C.; Gruz, J.; Skorepa, J.; Doležal, K.; Katsvanga, C.A.T.; Van Staden, J. Phytochemical Characterization, Antibacterial, Acetylcholinesterase Inhibitory and Cytotoxic Properties of Cryptostephanus vansonii, an Endemic Amaryllid. Phytother. Res. 2017, 31, 713-720. [CrossRef]

26. Hwang, S.H.; Wang, Z.; Suh, H.-W.; Lim, S.S. Antioxidant activity and inhibitory effects of 2-hydroxy-3-methylcyclopent-2-enone isolated from ribose-histidine Maillard reaction products on aldose reductase and tyrosinase. Food Funct. 2018, 9, 1790-1799. [CrossRef]

27. Xu, F.; Yang, J.; Negishi, H.; Sun, Y.; Li, D.; Zhang, X.; Hayashi, T.; Gao, M.; Ikeda, K.; Ikejima, T. Silibinin decreases hepatic glucose production through the activation of gut-brain-liver axis in diabetic rats. Food Funct. 2018, 9, 4926-4935. [CrossRef]

28. Assefa, A.D.; Jeong, Y.J.; Kim, D.J.; Jeon, Y.A.; Ok, H.C.; Baek, H.J.; Sung, J.S. Characterization, identification, and quantification of phenolic compounds using UPLC-Q-TOF-MS and evaluation of antioxidant activity of 73 Perilla frutescens accessions. Food Res. Int. 2018, 111, 153-167. [CrossRef]

29. Jun, H.I.; Kim, B.T.; Song, G.S.; Kim, Y.S. Structural characterization of phenolic antioxidants from purple perilla (Perilla frutescens var. acuta) leaves. Food Chem. 2014, 148, 367-372. [CrossRef]

30. Luthra, T.; Agarwal, R.; Estari, M.; Adepally, U.; Sen, S. A novel library of -arylketones as potential inhibitors of $\alpha$-glucosidase: Their design, synthesis, in vitro and in vivo studies. Sci. Rep. 2017, 7, 13246. [CrossRef]

31. Yang, Y.; Zhao, J.; Qiu, J.; Li, J.; Liang, X.; Zhang, Z.; Zhang, X.; Fu, H.; Korantzopoulos, P.; Letsas, K.P.; et al. Xanthine Oxidase Inhibitor Allopurinol Prevents Oxidative Stress-Mediated Atrial Remodeling in Alloxan-Induced Diabetes Mellitus Rabbits. J. Am. Heart Assoc. 2018, 7, e008807. [CrossRef]

32. Chang, T.-S. An Updated Review of Tyrosinase Inhibitors. Int. J. Mol. Sci. 2009, 10, 2440-2475. [CrossRef] [PubMed]

33. Rasouli, H.; Hosseini-Ghazvini, S.M.-B.; Adibi, H.; Khodarahmi, R. Differential $\alpha$-amylase/ $\alpha$-glucosidase inhibitory activities of plant-derived phenolic compounds: A virtual screening perspective for the treatment of obesity and diabetes. Food Funct. 2017, 8 , 1942-1954. [CrossRef] [PubMed]

34. Mettupalayam Kaliyannan Sundaramoorthy, P.; Kilavan Packiam, K. In vitro enzyme inhibitory and cytotoxic studies with Evolvulus alsinoides (Linn.) Linn. Leaf extract: A plant from Ayurveda recognized as Dasapushpam for the management of Alzheimer's disease and diabetes mellitus. BMC Complement. Med. Ther. 2020, 20, 129. [CrossRef] [PubMed]

35. Kim, H.H.; Kang, Y.-R.; Lee, J.-Y.; Chang, H.-B.; Lee, K.W.; Apostolidis, E.; Kwon, Y.-I. The Postprandial Anti-Hyperglycemic Effect of Pyridoxine and Its Derivatives Using In Vitro and In Vivo Animal Models. Nutrients 2018, 10, 285. [CrossRef] [PubMed]

36. Nauck, M.A.; Jensen, T.J.; Rosenkilde, C.; Calanna, S.; Buse, J.B. Neoplasms Reported With Liraglutide or Placebo in People With Type 2 Diabetes: Results From the LEADER Randomized Trial. Diabetes Care 2018, 41, 1663-1671. [CrossRef]

37. Van Dyke, A.L.; Lang Kuhs, K.A.; Shiels, M.S.; Koshiol, J.; Trabert, B.; Loftfield, E.; Purdue, M.P.; Wentzensen, N.; Pfeiffer, R.M.; Katki, H.A.; et al. Associations between self-reported diabetes and 78 circulating markers of inflammation, immunity, and metabolism among adults in the United States. PLoS ONE 2017, 12, e0182359. [CrossRef]

38. Sun, Y.; Zhu, M.; Zhao, H.; Ni, X.; Chang, R.; Su, J.; Huang, H.; Cui, S.; Wang, X.; Yuan, J.; et al. Serum Fibroblast Growth Factor 19 and Total Bile Acid Concentrations Are Potential Biomarkers of Hepatocellular Carcinoma in Patients with Type 2 Diabetes Mellitus. BioMed Res. Int. 2020, 2020, 1751989. [CrossRef]

39. Schlesinger, S.; Aleksandrova, K.; Pischon, T.; Jenab, M.; Fedirko, V.; Trepo, E.; Overvad, K.; Roswall, N.; Tjønneland, A.; BoutronRuault, M.C.; et al. Diabetes mellitus, insulin treatment, diabetes duration, and risk of biliary tract cancer and hepatocellular carcinoma in a European cohort. Ann. Oncol. 2013, 24, 2449-2455. [CrossRef]

40. Kim, D.; Ahn, B.-N.; Kim, Y.; Hur, D.Y.; Yang, J.W.; Park, G.B.; Jang, J.E.; Lee, E.J.; Kwon, M.J.; Kim, T.N.; et al. High Glucose with Insulin Induces Cell Cycle Progression and Activation of Oncogenic Signaling of Bladder Epithelial Cells Cotreated with Metformin and Pioglitazone. J. Diabetes Res. 2019, 2019, 2376512. [CrossRef]

41. Zheng, S.; Zhang, Z.; Qu, Y.; Zhang, X.; Guo, H.; Shi, X.; Cai, M.; Cao, C.; Hu, Z.; Liu, H.; et al. Radiopharmaceuticals and Fluorescein Sodium Mediated Triple-Modality Molecular Imaging Allows Precise Image-Guided Tumor Surgery. Adv. Sci. 2019, 6, 1900159. [CrossRef]

42. Yu, H.; Qiu, J.-F.; Ma, L.-J.; Hu, Y.-J.; Li, P.; Wan, J.-B. Phytochemical and phytopharmacological review of Perilla frutescens L. (Labiatae), a traditional edible-medicinal herb in China. Food Chem. Toxicol. 2017, 108, 375-391. [CrossRef] [PubMed]

43. Kagawa, N.; Iguchi, H.; Henzan, M.; Hanaoka, M. Drying the leaves of Perilla frutescens increases their content of anticancer nutraceuticals. Food Sci. Nutr. 2019, 7, 1494-1501. [CrossRef] [PubMed]

44. Naik, S.R.; Niture, N.T.; Ansari, A.A.; Shah, P.D. Anti-diabetic activity of embelin: Involvement of cellular inflammatory mediators, oxidative stress and other biomarkers. Phytomedicine 2013, 20, 797-804. [CrossRef]

45. Zhao, Y.; Pilvar, A.; Tank, A.; Peterson, H.; Jiang, J.; Aster, J.C.; Dumas, J.P.; Pierce, M.C.; Roblyer, D. Shortwave-infrared meso-patterned imaging enables label-free mapping of tissue water and lipid content. Nat. Commun. 2020, 11, 5355. [CrossRef] [PubMed]

46. Qin, Z.; Wang, W.; Liao, D.; Wu, X.; Li, X.E. UPLC-Q/TOF-MS-Based Serum Metabolomics Reveals Hypoglycemic Effects of Rehmannia glutinosa, Coptis chinensis and Their Combination on High-Fat-Diet-Induced Diabetes in KK-Ay Mice. Int. J. Mol. Sci. 2018, 19, 3984. [CrossRef]

47. Orozco, L.D.; Morselli, M.; Rubbi, L.; Guo, W.; Go, J.; Shi, H.; Lopez, D.; Furlotte, N.A.; Bennett, B.J.; Farber, C.R.; et al. Epigenome-wide association of liver methylation patterns and complex metabolic traits in mice. Cell Metab. 2015, 21, 905-917. [CrossRef] 
48. Ye, L.; Mueller, O.; Bagwell, J.; Bagnat, M.; Liddle, R.A.; Rawls, J.F. High fat diet induces microbiota-dependent silencing of enteroendocrine cells. eLife 2019, 8, e48479. [CrossRef]

49. Zheng, Y.; Lee, S.; Liang, X.; Wei, S.; Moon, H.G.; Jin, Y. Suppression of PTRF alleviates the polymicrobial sepsis induced by cecal ligation and puncture in mice. J. Infect. Dis. 2013, 208, 1803-1812. [CrossRef]

50. E Nico, E.T.; de Oliveira, P.R.; de Souza, L.P.; Pereira, F.D.; Delbin, M.A.; Zanesco, A.; Camargo-Mathias, M.I. The action of aminoguanidine on the liver of trained diabetic rats. J. Diabetes Metab. Disord. 2013, 12, 40. [CrossRef]

51. Veal, E.A.; Day, A.M.; Morgan, B.A. Hydrogen peroxide sensing and signaling. Mol. Cell 2007, 26, 1-14. [CrossRef]

52. Houstis, N.; Rosen, E.D.; Lander, E.S. Reactive oxygen species have a causal role in multiple forms of insulin resistance. Nature 2006, 440, 944-948. [CrossRef] [PubMed]

53. Zhuang, Y.; Wu, H.; Wang, X.; He, J.; He, S.; Yin, Y. Resveratrol Attenuates Oxidative Stress-Induced Intestinal Barrier Injury through PI3K/Akt-Mediated Nrf2 Signaling Pathway. Oxid. Med. Cell. Longev. 2019, 2019, 7591840. [CrossRef] [PubMed] 